\title{
Machine Learning and Fuzzy Logic in Electronics: Applying Intelligence in Practice
}

\author{
Malinka Ivanova ${ }^{1, *(\mathbb{D})}$, Petya Petkova ${ }^{2}$ and Nikolay Petkov ${ }^{2}$ \\ 1 Faculty of Applied Mathematics and Informatics, Technical University of Sofia, 1000 Sofia, Bulgaria \\ 2 College of Energy and Electronics, Technical University of Sofia, 1000 Sofia, Bulgaria; \\ petya.petkova@tu-sofia.bg (P.P.); ntoshevp@abv.bg (N.P.) \\ * Correspondence: m_ivanova@tu-sofia.bg
}

Citation: Ivanova, M.; Petkova, P.; Petkov, N. Machine Learning and Fuzzy Logic in Electronics: Applying Intelligence in Practice. Electronics 2021, 10, 2878. https://doi.org/ 10.3390 /electronics 10222878

Academic Editor: Valentina E. Balas

Received: 16 October 2021

Accepted: 18 November 2021

Published: 22 November 2021

Publisher's Note: MDPI stays neutral with regard to jurisdictional claims in published maps and institutional affiliations.

Copyright: (c) 2021 by the authors. Licensee MDPI, Basel, Switzerland. This article is an open access article distributed under the terms and conditions of the Creative Commons Attribution (CC BY) license (https:// creativecommons.org/licenses/by/ $4.0 /)$.

\begin{abstract}
The paper presents an analysis and summary of the current research state concerning the application of machine learning and fuzzy logic for solving problems in electronics. The investigated domain is conceptualized with aim the achievements, trending topics and future research directions to be outlined. The applied research methodology includes a bibliographic approach in combination with a detailed examination of 66 selected papers. The findings reveal the gradually increasing interest over the last 10 years in the machine learning and fuzzy logic techniques for modeling, implementing and improving different hardware-based intelligent systems.
\end{abstract}

Keywords: electronics; machine learning; fuzzy logic; neural networks; intelligent devises; sensors; Internet of Things; robotics

\section{Introduction}

In the last three decades, there has been a tremendous expansion of digitalization and electronization. Nowadays, even the "digital native born" are familiar with the usage of electronic devices, smart phones and all kinds of intelligent systems, which are integral parts of our daily life. Everyone is immersed in the ocean of information and communication technologies and utilized artificial intelligence solutions in the form of software or hardware approaches. The simulation of human intelligence by machines is called artificial intelligence. These are programs, applications and interfaces that create the predefined reality with the preliminary known or predicted best situations.

Machine learning is a part of artificial intelligence science and works in close collaboration with data science [1,2]. The main aim is for the collected big data to be processed and studied in such a way to give meaningful knowledge when problems have to be solved or decisions have to be made. The reviled patterns and anomalies lead to further understanding of a wide variety of events, processes, or phenomena. Machine learning is also responsible for the development and improvement of algorithms, dealing with more general or more specific tasks, with possibilities for application in different contexts [3]. Deep learning, as a subarea of machine learning, which utilizes neural-network-based algorithms, is often the preferred method for resolving scientific and real-world problems [4].

Every day, a large amount of data is generated and stored by companies, organizations and research departments as some of them need further processing for knowledge extraction, summarization, or conceptualization. Electronics science and industry is no exception [5]. Both of them try to take all benefits and advantages of machine learning to automate, improve and support multiple engineering tasks [6]. This requires more research efforts in software and hardware engineering for satisfaction of some intelligence levels. The collected data after experiments or simulations could be used for further explanation regarding the electrical behavior of electronic devices, for the prediction of some circuit functions or for the analysis of their different parameters and characteristics. Finding the precise position of object [7], map creation from sensors data [8] and manipulation of 
deformable objects [9] are a small part of the research problems that require the application of machine learning techniques. The intention of this work is to identify the most common applications of machine learning for solving simpler or more complex problems in electronics.

Fuzzy logic is another scientific field that is used for modeling, description and evaluation of objects and systems with different levels of complexity, which are characterized with uncertainty, fuzziness and vagueness of their parameters and properties [10]. The employed logical rules together with the created knowledge base lead to fuzzy or crisp inference that could point out one or another solution. In electronics, fuzzy logic is most often used for modeling and improvement of electronic devices, systems and processes, considering the dynamic changes of conditions and environmental settings [11]. Algorithms and techniques for fuzzy logic realization are in continuous evolvement, striving to assist a wide variety of engineering activities. Some software and hardware systems are developed on the base of fuzzy logic in assistance and support of engineers who are responsible for the design, analysis, testing and diagnosis of electronics modules and devices.

The aim of the paper is to analyze and summarize the current scientific achievements regarding the application of machine learning and fuzzy logic in the implementation or improvement of different electronic devices and systems and to create a conceptual framework, showing the trending topics and future directions for research.

\section{Methodology}

The methodology of this exploration combines bibliometric analysis with visual presentations and a detailed review of 66 selected scientific papers, as presented on Figure 1.

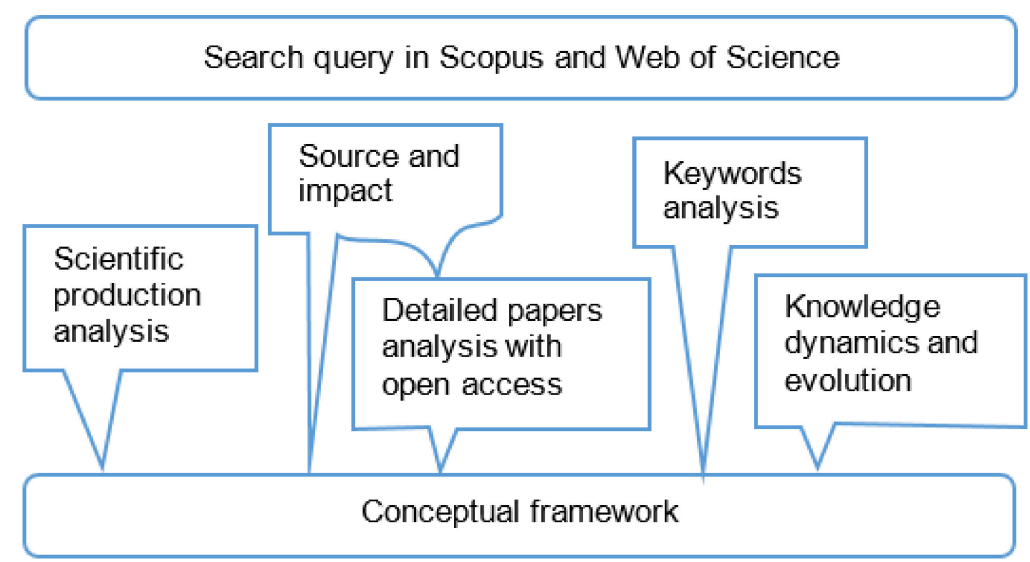

Figure 1. Used methodology.

Bibliometric analysis is an approach used by researchers to map scientific knowledge regarding examined topics in a certain domain $[12,13]$. This allows conceptualization creation of the researched areas, giving information about the past and current scientific production as well as drawing some trends and future research directions. The created bibliometric maps and figures are based on bibliographic data, taken from the scientific databases Scopus and Web of Science according to forming search queries: "machine learning and electronics" and "fuzzy logic and electronics". The received results after time filtering (the indexed papers from 2011 to 2020 year are considered) and arranged by their relevance are extracted and proceed with Biblioshiny package [14], which is part of the R software for statistical computing. The conceptual framework development for the usage of machine learning algorithms and fuzzy logic methods for problem solving in electronics considers the following:

- the summarized and visualized information about annual scientific production,

- the number of citations,

- the country of the corresponding author,

- the sources of the published papers and their h-index, 
- the most used author's keywords and generated keywords plus,

- the created maps with trending topics and knowledge evolution.

Additionally, for a deeper understanding of the investigated scientific domain, 66 scientific papers with open access are examined, selected from the most relevant and with the highest h-index sources.

\section{Machine Learning Utilization}

In this section, machine learning usage in electronics is described through examining the "big picture", applying a bibliometric approach [15] and systematic review of selected scientific papers. A conceptual summarization, concerning the recent research topics, the annual scientific production, the main sources that publish these scientific papers, trending topics and thematic evolution, is performed because it is seen as an important approach for understanding the current scientific interests, research preferences and achieved findings. The examination was conducted over two weeks-from 12 July 2021 to 30 July 2021—taking the bibliographic data from indexing scientific databases Scopus and Web of Science. The first query is generated by the keywords: machine learning and electronics. The search is conducted in the papers' title, abstract and authors' keywords of the indexed documents in the period from 2011 to 2020 . The returned results are ordered according to their relevance.

\subsection{Scientific Production}

In the Scopus database, 1535 documents are found, in which 3672 keywords are employed by 4893 authors. The authors of single-authored documents are 79; the authors of multi-authored documents are 4814; the coefficient, showing co-authors per documents, is 4.08; and the collaboration index is 3.46 .

In the scientific database Web of Science, a smaller number of documents (434) is identified, written by 1810 authors as the authors of single-authored documents are 27 and the authors of multi-authored documents are 1783. The coefficient, presenting co-authors per documents, is 4.72 , and the collaboration index is 3.38 .

It seems that a big part of the indexed documents in Scopus and Web of Science are prepared in collaboration among several authors as the countries of the corresponding authors with the biggest contribution according to Scopus are: USA, China, India, Japan, and Germany (Figure 2). The parameter Multiple Countries Publication (MCP) measures the international collaboration as at least one co-author should be from another country. The parameter Single Country Publication (SCP) indicates that the corresponding author and his co-authors are from one country.

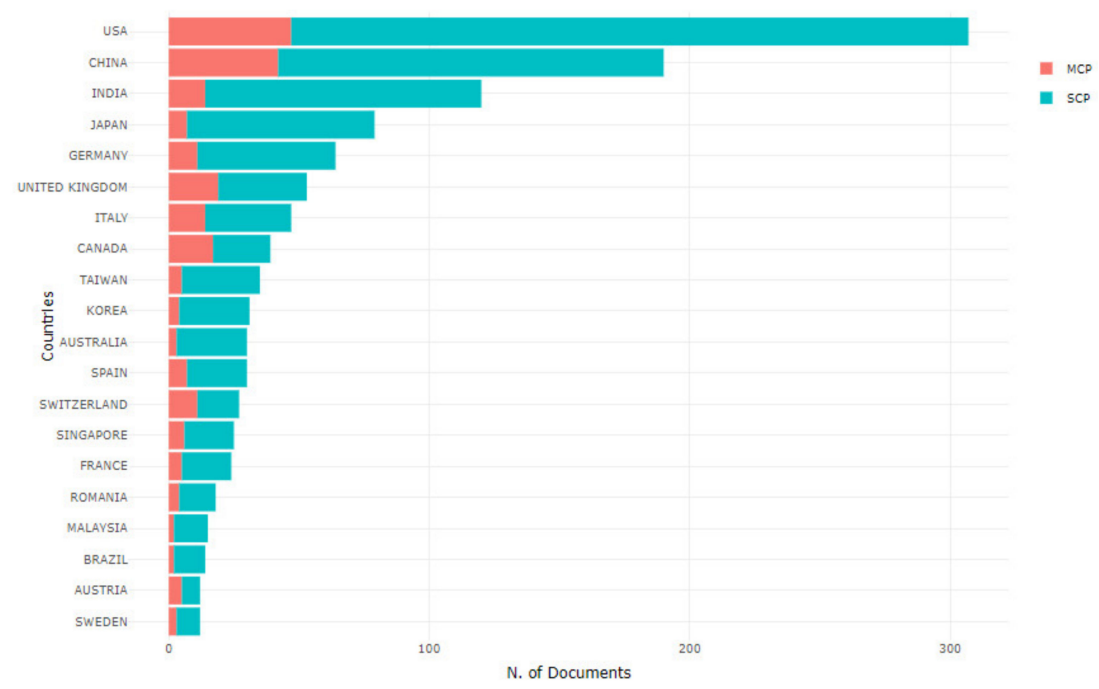

Figure 2. Countries of the corresponding authors with the biggest contribution to the explored topic according to Scopus and collaboration parameters. 
The annual scientific production in the period from 2011 to 2020 is presented in Figure 3: for 2011, 35 documents are indexed in Scopus; for 2012, 58; 2013, 63; 2014, 65; 2015,$60 ; 2016,81 ; 2017,120 ; 2018,223 ; 2019,384 ; 2020,446$. The observed tendency is described with an increasing curve that can be explained with enhanced interest to this topic by researchers. No jumps causing turning points are visible on the curves. Contrariwise, the curve smoothly raises as the calculated annual growth rate is $32.68 \%$. The annual scientific production indexed in Web of Science is also described with a smoothly increasing curve as the found documents for 2011 year are 8; for 2012 and 2013, 16; 2014, $15 ; 2015,16 ; 2016,33 ; 2017,44 ; 2018,54 ; 2019,107 ; 2020,121$.

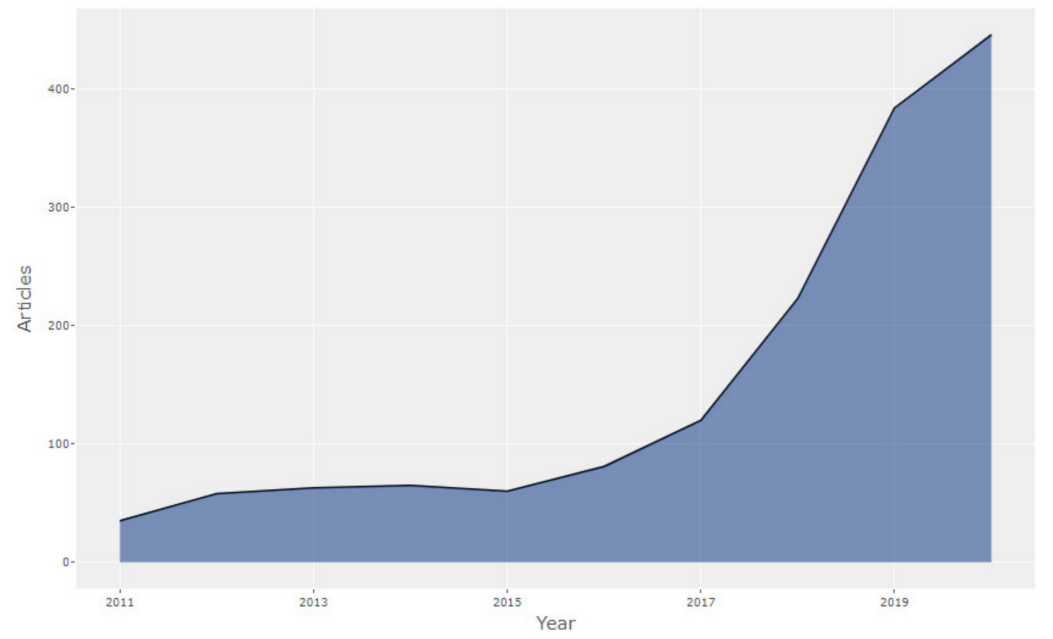

Figure 3. Annual scientific production according to Scopus.

The USA, China, UK, India, Canada, Switzerland, Italy, Japan, Germany, and the Netherlands are among the most cited countries. The maximal value of the average citations per documents, indexed in Scopus, is 8.5, obtained for 2017 (Figure 4).

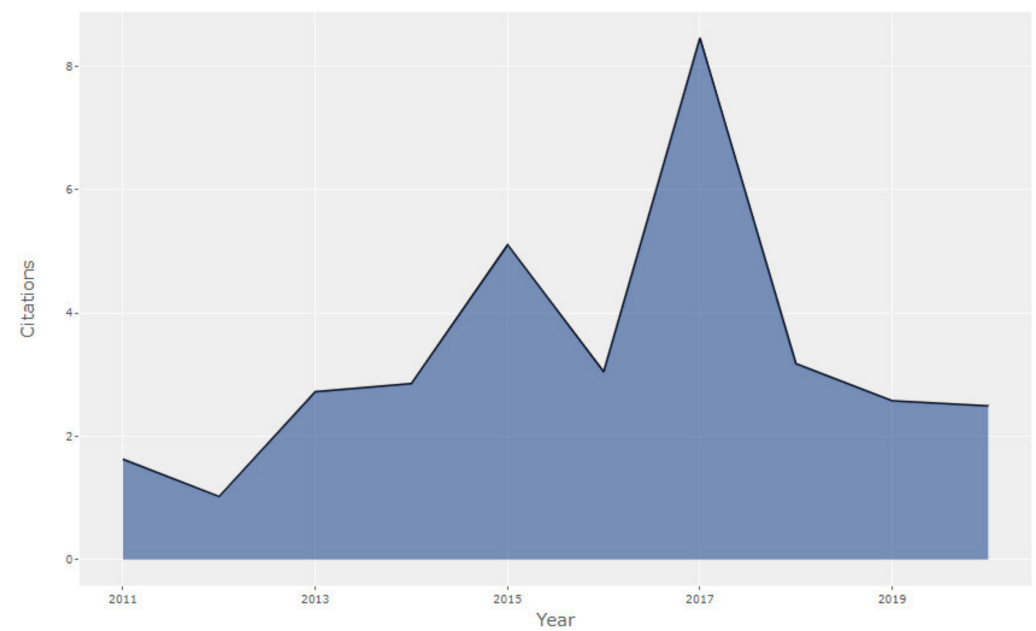

Figure 4. Average article citations per year according to Scopus.

\subsection{Characteristics of Sources}

Receiving information about the sources of published papers and their impact gives an opportunity for detailed investigation into the topics of research interest. The intention is concrete papers and their discussed problems to be further explored for outlining some important key research points and main scientific themes. For this purpose, the results from the bibliographic analysis are used to point out the most influential sources. According to the Scopus database, the papers are published mainly in different conference proceedings, journals and books; the twenty most relevant sources are presented on Figure 5. After the 
source grouping, it is evident that the most relevant proceedings are from the following scientific forums:

- Industrial Electronics Conference,

- IEEE International Symposium on Industrial Electronics,

- International Symposium on Low Power Electronics and Design,

- Annual Conference of the IEEE Industrial Electronics Society,

- SPIE conferences, organized by the International Society for Optical Engineering, and the most preferred journals and books are:

- IEICE Transactions on Information and Systems,

- Lecture Notes in Electrical Engineering,

- IEEE Access,

- Sensors,

- Lecture Notes in Computer Science,

- IEEE Journal of Solid-State Circuits,

- Scientific Reports.
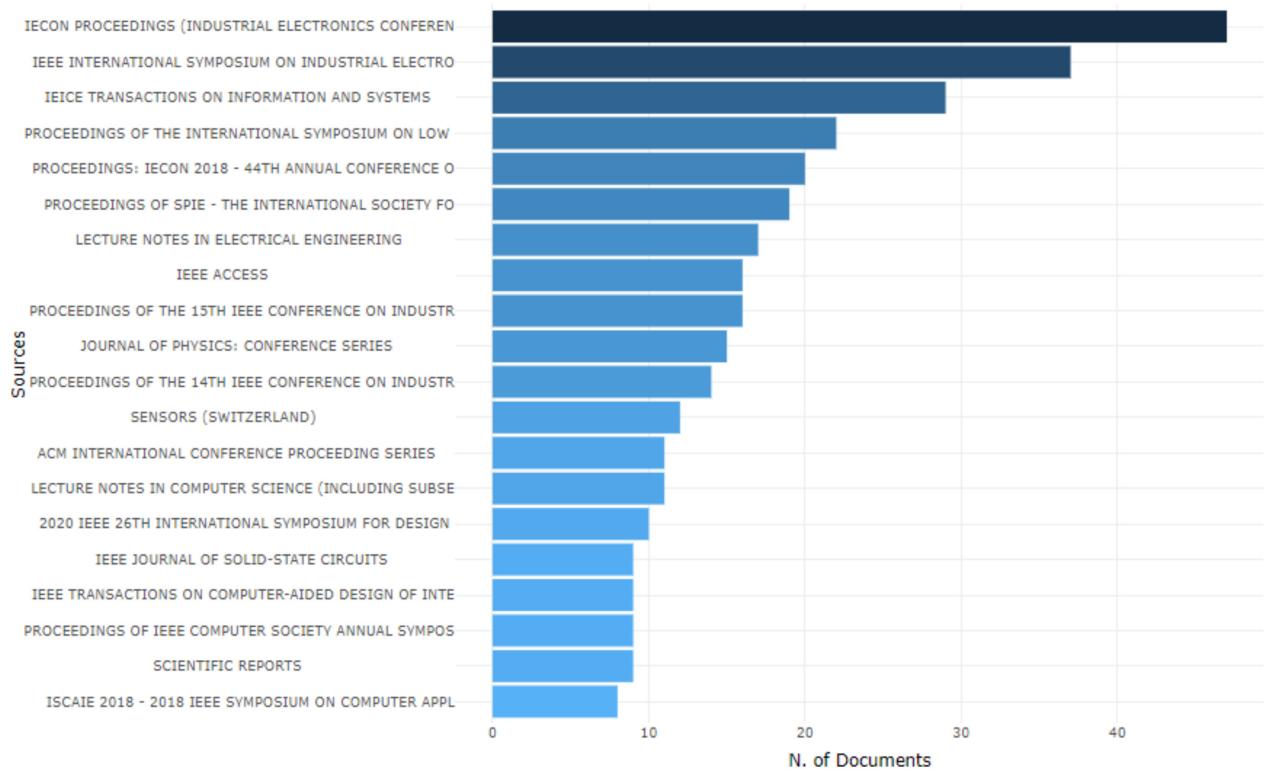

Figure 5. The most relevant sources according to Scopus.

According to the bibliographic data extracted from Web of Science, the top sources are the following scientific journals: IEEE Access, Scientific Reports, Journal of Instrumentation, Sensors, ACS Applied Materials \& Interfaces, Applied Sciences-Basel, Electronics, Elektronika ir Elektrotechnika, IEEE Consumer Electronics Magazine, IEEE Journal of Solid-State Circuits. The obtained results show that the conference proceedings include a smaller collection of the scientific papers in comparison to the journal contributions.

Bradford's law is depicted on Figure 6 (according to Scopus). It presents the number of sources in the first zone (so called core sources), which have the biggest contribution for papers publication in the explored scientific area. According to this law, the journals are grouped in three zones, as the number $n$ of the published papers related to the examined topic forms a geometric series: $1: \mathrm{n}: \mathrm{n}^{2}: \mathrm{n}^{3}$. In the case of the query "machine learning and electronics", the first zone includes 49 sources, mainly journals and conference proceedings, as the number of all sources is 821. The curve, which describes Bradford's law and is constructed according to the Web of Science database, has a similar form; in the first zone, there are 57 sources from 347. 


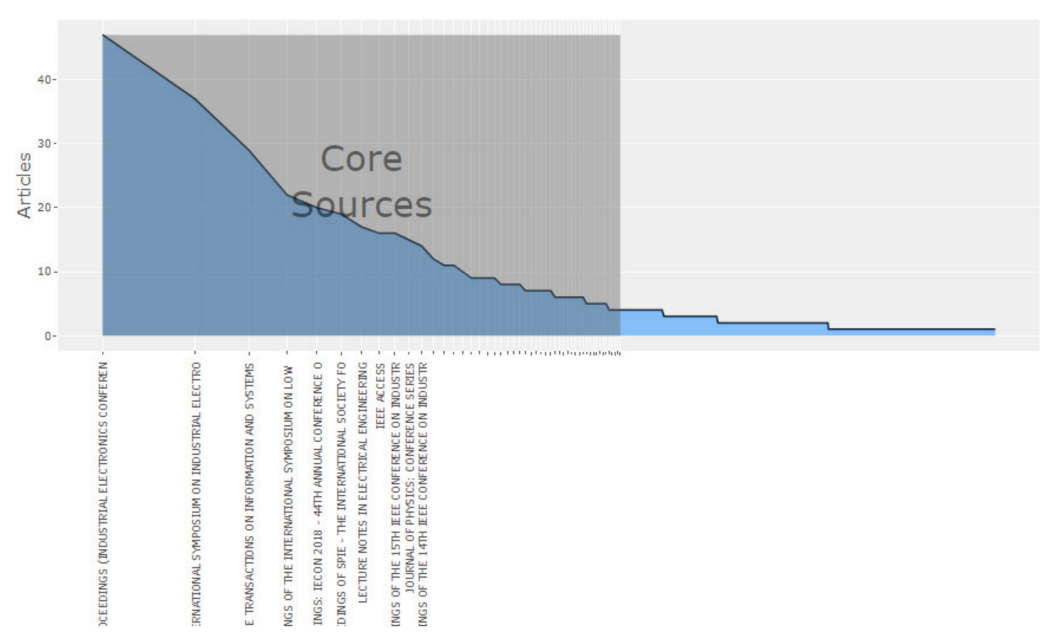

Figure 6. Bradford's Law according to Scopus.

It is noticeable that the number of sources with open access among the most relevant ones remains low; according to Scopus, only IEICE Transactions on Information and Systems and Journal of Physics: Conference Series have open access. According to Web of Science: Sensors, ACS Applied Materials \& Interfaces, Applied Sciences-Basel, Electronics, and Elektronika ir Elektrotechnika are open access.

The source importance could be evaluated through different parameters; one of the most popular is the Hirsch index (h-index). The h-index is a measure, showing the number of published papers $h$ as each paper must be cited at least $h$ times. The sources with the highest impact concerning h-index are summarized in Table 1 according to Scopus and Web of Science. The results are gathered separately, searching in Scopus and Web of Science. Then, the sources are combined and arranged in the direction of higher to lower h-index.

Table 1. h-index of sources according to Scopus and Web of Science.

\begin{tabular}{cc}
\hline Source & h-Index \\
\hline Nature Communications (Scopus) & 365 \\
\hline Physical Review A (Scopus) & 283 \\
\hline IEEE Journal of Solid-State Circuits (Scopus) & 215 \\
\hline Scientific Reports (Scopus) & 213 \\
\hline Proceedings of SPIE-The International Society for Optical Engineering (Scopus) & 176 \\
\hline Sensors (Switzerland) (Scopus and Web of Science) & 172 \\
\hline Neural Networks (Scopus) & 148 \\
\hline Neurocomputing (Scopus) & 143 \\
\hline IEEE Access (Scopus and Web of Science) & 127 \\
\hline IEEE Transactions on Computer-Aided Design of Integrated Circuits and Systems (Scopus) & 119 \\
\hline Energies (Web of Science) & 93 \\
\hline Journal of Physics: Conference Series (Scopus) & 85 \\
\hline Proceedings of the International Symposium on Low Power Electronics and Design (Scopus) & 71 \\
\hline IEEE International Symposium on Industrial Electronics (Scopus) & 61 \\
\hline Applied Sciences (Web of Science) & 53 \\
\hline Proceedings of IEEE Computer Society Annual Symposium On VLSI, ISVLSI (Scopus) & 26 \\
\hline
\end{tabular}




\subsection{Trending Research Topics}

The important key points in research are identified after more detailed exploration of the used authors' keywords. For this purpose, Table 2 summarizes thirty keywords used in the papers with the biggest frequency of occurrences according to Scopus. The author's keywords are defined as keywords that are written by authors who believe that these keywords in the best way describe the discussed content in the paper.

Table 2. Author's keywords and their occurrences according to Scopus.

\begin{tabular}{cc}
\hline Author's Keywords and Frequency of Occurrences \\
\hline machine learning-522 \\
neural networks-50 \\
classification-38 & deep learning-73 \\
artificial intelligence-41 \\
support vector machine-27 \\
clustering-19 & Internet of Things-34 \\
low power-23 \\
convolutional neural networks-17 \\
anomaly detection-16 & energy efficiency-17 \\
reinforcement learning-16 & fpga-15 \\
pattern recognition-15 & edge computing-15 \\
sentiment analysis-14 & random forest-14 \\
fault diagnosis-13 & power electronics-14 \\
neuromorphic computing-13 & computer vision-13 \\
spiking neural networks-11 & image processing-12 \\
robotics-10 & wireless sensor networks-11 \\
support vector machine-10 & Internet of Things-10 \\
\end{tabular}

Keywords plus could additionally contribute to the "big picture" creation and better paper focus understanding, concerned topics and discussed problems. Keywords plus are automatically generated, pointing out the words that are most often included in the titles of the referenced papers. Table 3 presents the keywords plus and their occurrences according to the Scopus database.

Table 3. Keywords plus occurrences according to Scopus.

\begin{tabular}{cc}
\hline \multicolumn{2}{c}{ Keyword Plus and Their Occurrences } \\
\hline learning systems-692 & machine learning-508 \\
artificial intelligence-329 & low power electronics-280 \\
learning algorithms-254 & neural networks-220 \\
industrial electronics-213 & energy efficiency-120 \\
classification of information-118 & deep learning-115 \\
forecasting-112 & Internet of Things-112 \\
power electronics-104 & support vector machines-103 \\
electronics industry-100 & electronics-94 \\
data mining-90 & decision trees-76 \\
\hline
\end{tabular}

Trending research topics are drawn after the analysis of authors' keywords and constructed visual view. Figure 7 shows the trending map for a period of 7 years-from 2014 to 2020 according to the Scopus database. The trending topics for 2020 year are described with the authors' keywords: Internet of Things, power electronics, image processing, edge computing, random forest algorithm. 


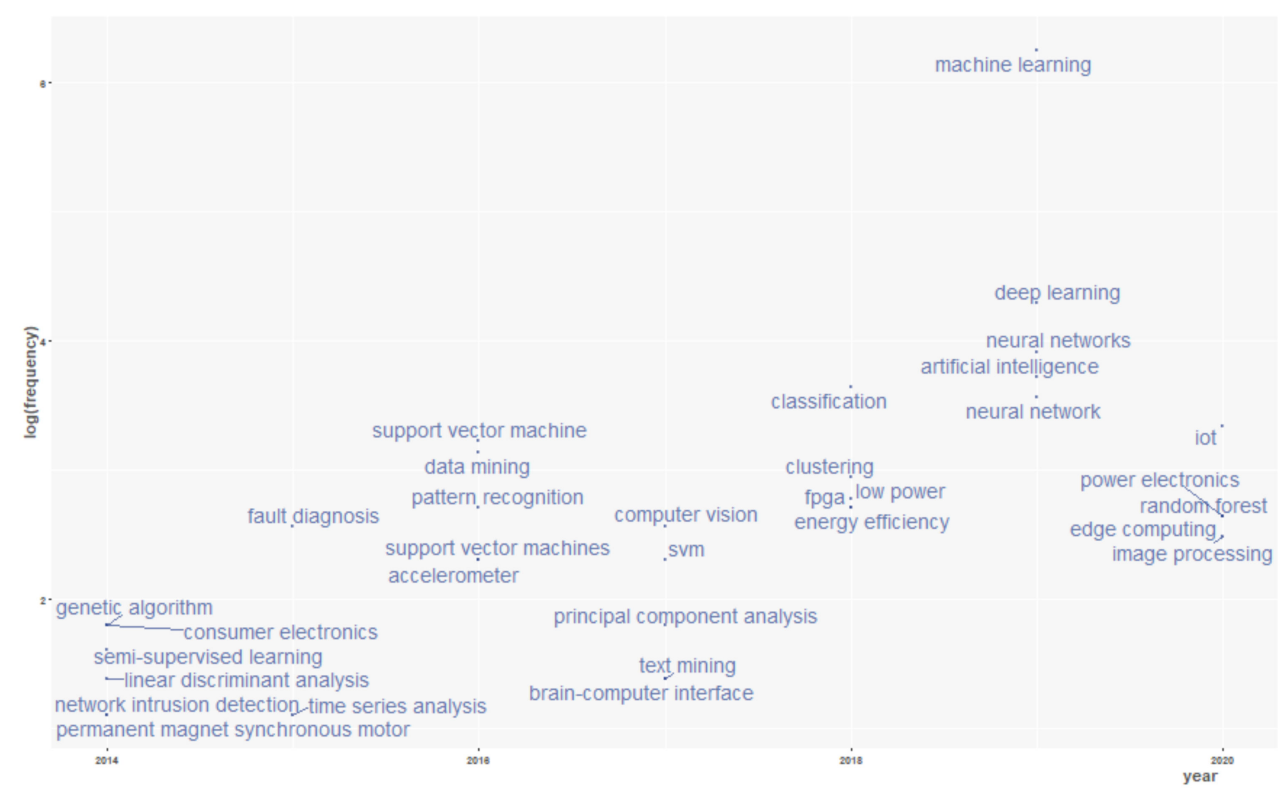

Figure 7. Trending topics according to Scopus.

\subsection{Thematic Evolution}

The scientific knowledge dynamics and knowledge evolution are grasped through the generation of some thematic maps, which are created after applying the clustering algorithm Louvain regarding the most utilized 500 authors' keywords. Each thematic map consists of four quadrants as each quadrant shows one or more main themes/clusters. The first quadrant includes so-called "motor" clusters, the second quadrant collects "highly developed and insolated" themes, the third quadrant "emerging or declining" clusters and the fourth quadrant "basic and transversal" themes. Additionally, a thematic map is characterized by two main parameters: (1) centrality, which is related to the theme importance and (2) density, which concerns the theme development. Each cluster on the thematic map is presented through a bubble, whose name is a word with the highest occurrence in this cluster. The bigger bubbles are characterized by a higher frequency of word occurrence. The themes evolution can be studied as the examined period (2011-2020 year) is divided to time slices. Here, four time-slices are formed, taking into account the curve form of the annual scientific production (see Figure 3): time slice 1 reflects on the period 2011-2014, time slice 2 summarizes the 2015-2016 years, time slice 3 includes 2017-2018 years and time slice 4 describes 2019-2020 years.

In the first time slice, presented on Figure 8, the "motor" cluster is machine learning, which includes several other important keywords such as: classification, fault diagnosis, computer vision, pattern recognition, feature extraction, human-computer interaction, condition monitoring, defect prediction, consumer electronics. Neural networks and genetic algorithms are also classified as "motor" themes. In the "emerging or declining" quadrant is the theme sentiment analysis. The "basic and transversal" themes are: support vector machines (other valuable keywords in this cluster are wireless sensor networks and anomaly detection), accelerometer and data mining. It can be noticed that a big part of the cluster names are keywords typical for machine and deep learning scientific fields, data science and computational linguistics (sentiment analysis). Only the accelerometer (electronic device used for example in vehicle control system) cluster pertains to the electronics' domain. 


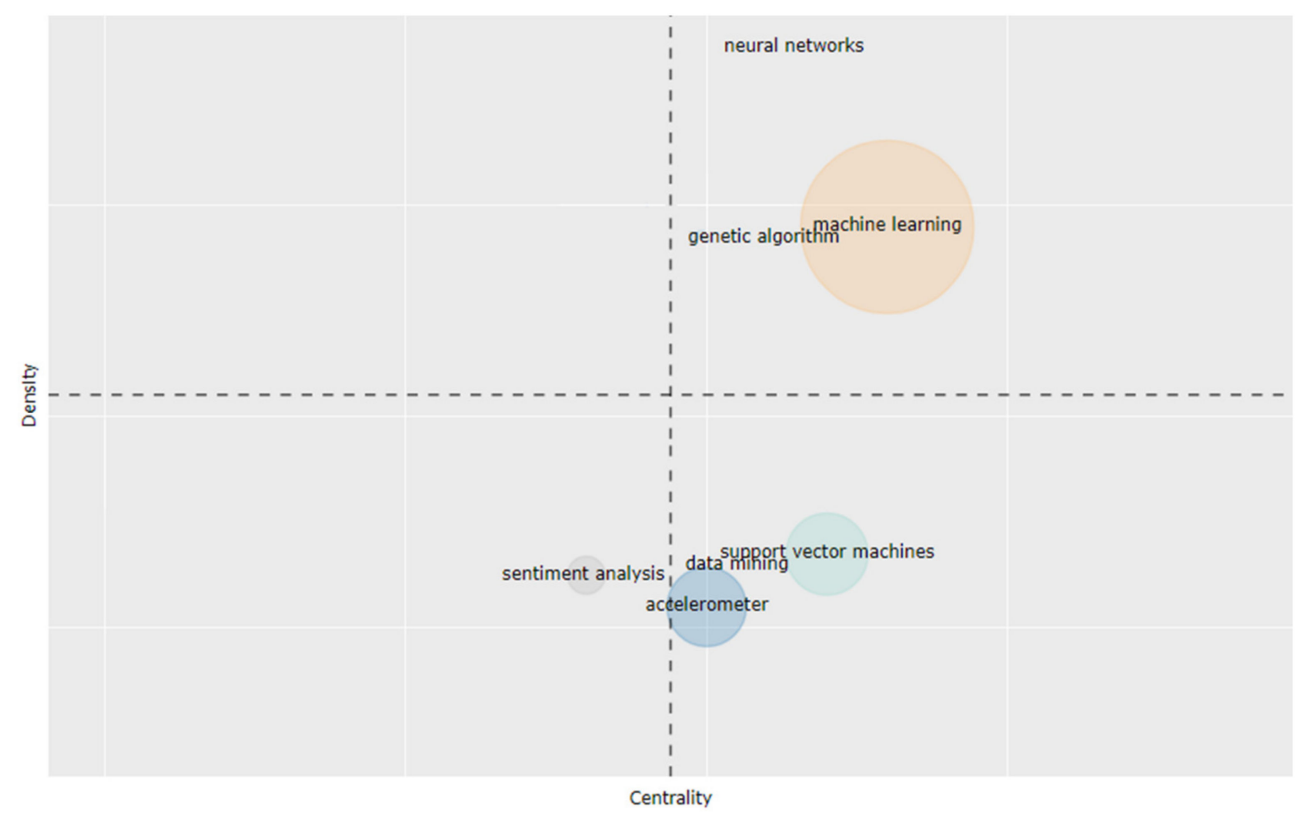

Figure 8. Thematic map, time slice 1.

This time slice characterizes the period from 2011 to 2014 year, when the "motor" clusters are machine learning, neural networks and genetic algorithms. The machine learning cluster is presented with the biggest bubble in comparison to the other clusters on the map, which indicates the biggest research interest and contribution to this topic. Support vector machine is a machine learning algorithm and is separated in a different cluster, placed into the "basic and transversal" themes. It means that especially this algorithm is so popular in the first observed time slice among researchers, and it is utilized in different scientific works. The cluster accelerometer is not placed in the center that is related to its not-so-big importance for research according to the parameter centrality.

In time slice 2 (Figure 9), the "motor" theme is related to neural network and the "highly developed and insolated" themes are connected to the keywords low-power design and artificial intelligence. The theme support vector machine is seen as a "emerging or declining" cluster. In this case, it is a "declining" cluster because in the next time slices it does not appear as a separate cluster as this keyword is included in other clusters. In the fourth quadrant, "basic and transversal" themes include Internet of Things (IoT), industry 4.0, machine learning and classification. In time slice 1, the keyword classification was part of the cluster machine learning, while here it forms a separate cluster. The closest cluster to the center of the coordinate system is artificial intelligence that could be explained with the theme "importance and progressive development" in this time slice.

It seems that during these two years (2015 and 2016), the popularity of machine learning for solving a wide variety of problems in electronics increases as it is converted from "motor" cluster to "basic and transversal". Algorithms for classification are separated in different clusters that draw their importance from the investigated domain. Internet of Things and Industry 4.0 are formed as different clusters as the first one is more developed, taking into account the parameter Density. The "motor" cluster in this time slice is neural network, which is connected to its possibility for deciding deep learning tasks. The bubble is bigger than this in time slice 1, which shows a higher number of scientific papers that utilize neural network apparatus. 


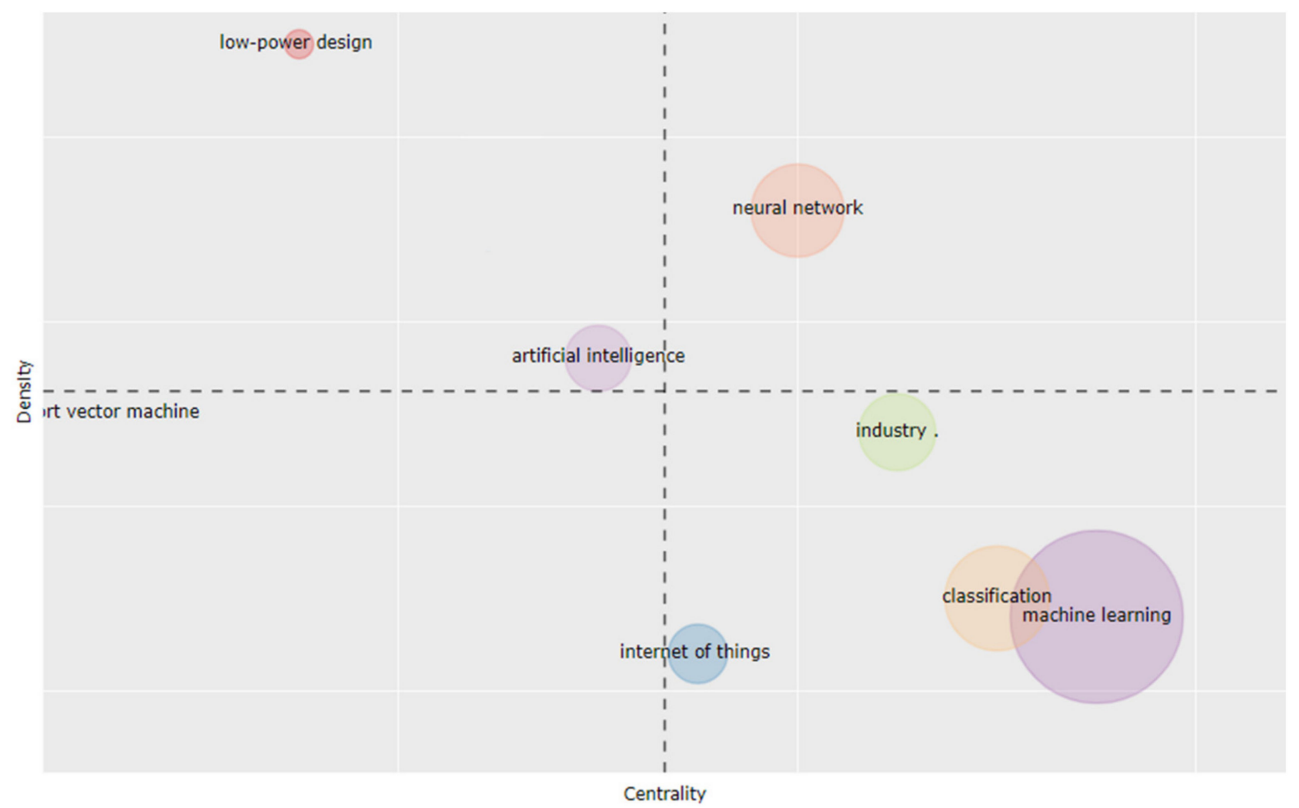

Figure 9. Thematic map, time slice 2.

In the third time slice (Figure 10) the "motor" theme is classification, which includes keywords feature extraction, fault detection and big data. The second quadrant "highly developed and insolated" themes consist of three clusters: condition monitoring, security and power electronics, as the optimization cluster is placed on the boundary between the second and third quadrant. In the third quadrant, "emerging or declining" clusters are grouped in artificial neural networks, recurrent neural networks and organic electronics themes. The fourth quadrant "basic and transversal" theme includes neural network, IoT, machine learning and neuromorphic computing.

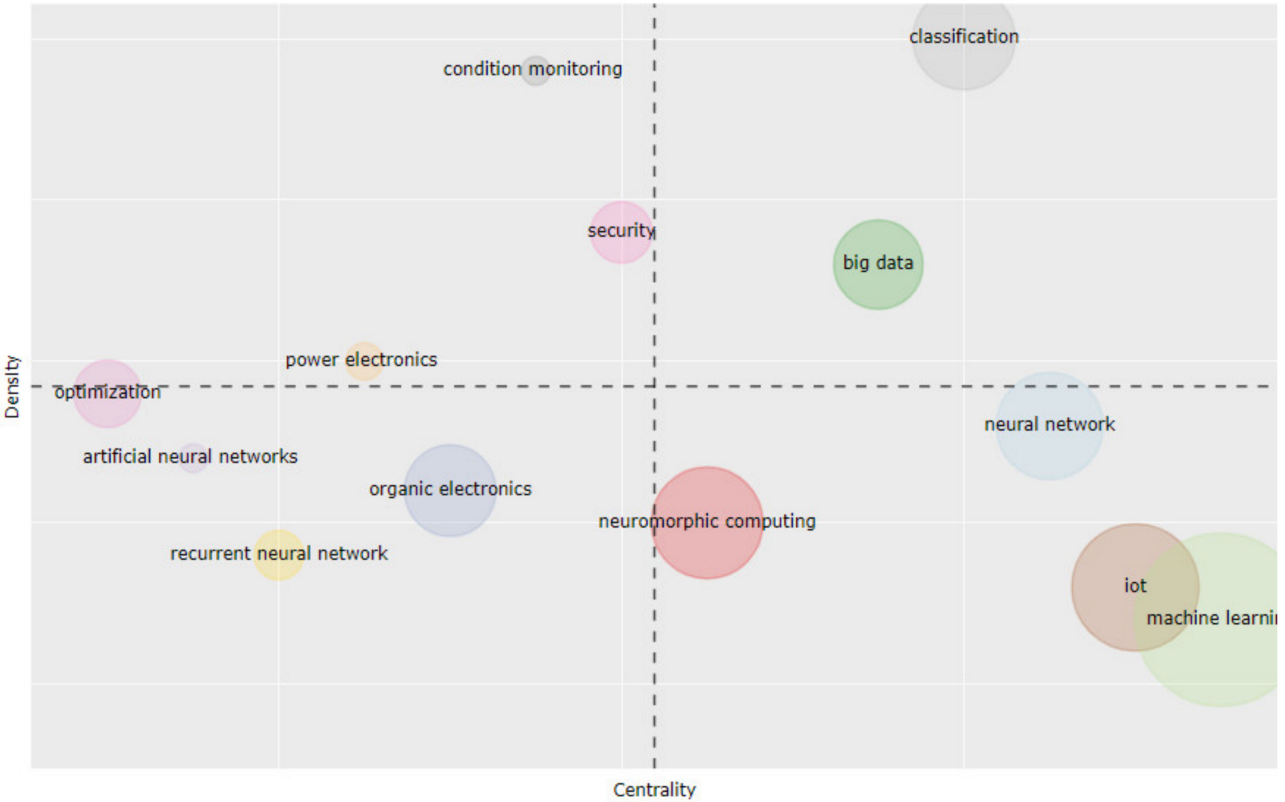

Figure 10. Thematic map, time slice 3.

In this time period (2017-2018), the cluster machine learning continues to be popular in scientific society and is placed in the "basic and transversal" quadrant. The cluster classification is removed from the "basic and transversal" themes, becoming the "motor" topic. The opposite can be said for neural networks, whose cluster is moved from "motor" 
themes to the "basic and transversal" quadrant. Obviously, the research attention is focused on big data and how the classification problems could be decided.

The "motor" clusters in time slice 4 (Figure 11) are formed around the keywords Internet of Things, neural networks and artificial neural networks. The wireless sensor networks, electronics and sentiment analysis are classified as "highly developed and insolated" themes. The "emerging or declining" clusters are topics related to low power and neuromorphic. The fourth quadrant includes "basic and transversal" themes: power electronics, IoT, machine learning and reinforcement learning. It can be observed that in this time slice, more sector names are keywords, typical for the electronics domain. It means that the mutual connection among keywords from the scientific areas of machine learning and electronics is strengthened in comparison to the previous time slices.

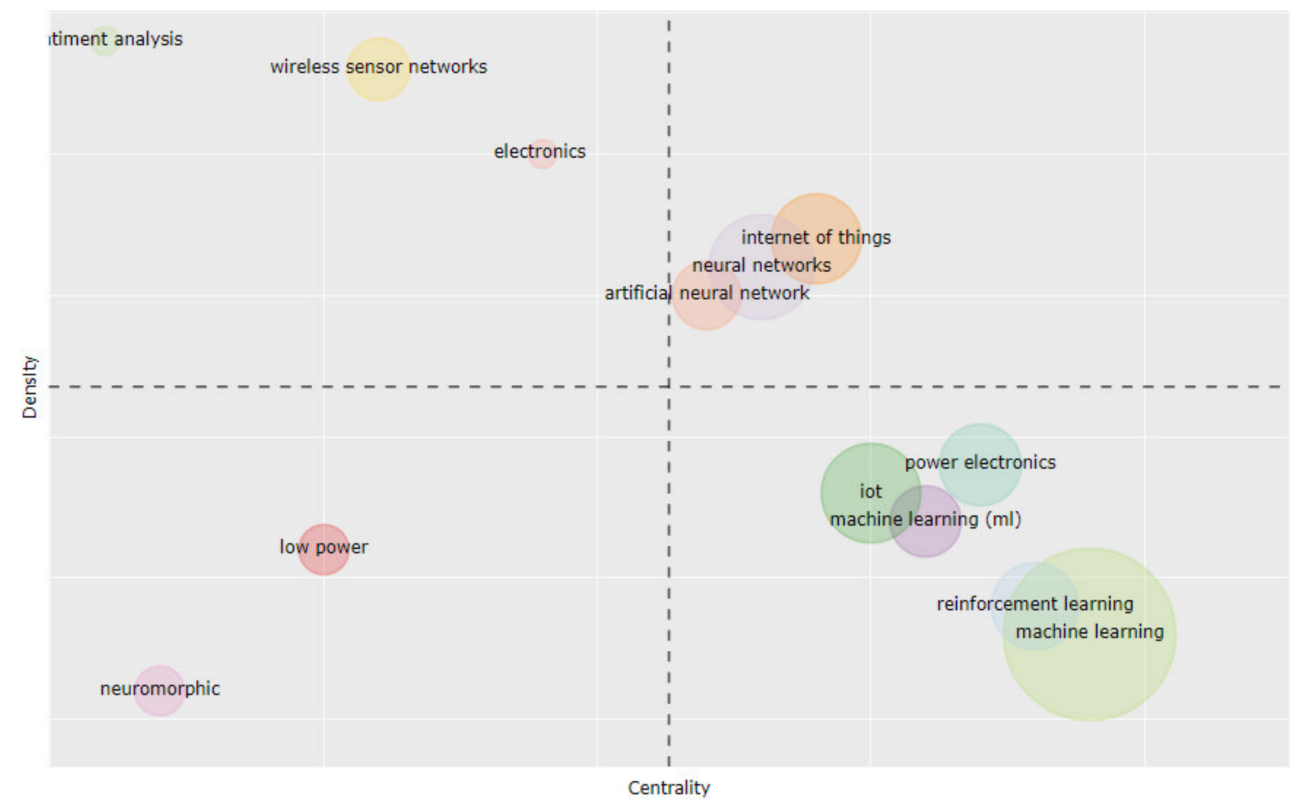

Figure 11. Thematic map, time slice 4 .

In this period (2019-2020), the machine learning cluster remains its place in the "basic and transversal" quadrant, continuing to be in the center of the scientific interest. The classification cluster is absorbed by the machine learning cluster, stopping to present a separate research topic. A new cluster, reinforcement learning, is formed, which is detached from the machine learning cluster. Neural networks are again among the "motor" themes, confirming their importance in scientific development.

If we consider the time slice position of the theme machine learning on the thematic maps and investigate it, its changeable mode is visible. In time slice 1, machine learning is a "motor" theme; in the next three time slices, it is classified into the "basic and transversal" cluster. Its position in the fourth quadrant is also changeable. The motion is visible from a more central to more peripheral place and again back to a more central position. This cluster content is also changeable as some merges and divergences with other themes are noted.

The cluster neural networks is also characterized by its dynamics. In the first time slice, although it is placed among the "motor" clusters, it is presented with a very small point that indicates smaller scientific production devoted to this research topic. The interest in the neural networks increases in the next time slices, as during periods 2 and 4 , they form bigger "motor" clusters. In time slice 3, two clusters related to neural networks emerge: artificial neural networks and recurrent neural networks, which are placed in "emerging or declining" themes. 
While the clusters low-power design and Internet of Things emerge in time slice 2, the cluster power electronics is formed in time slice 3 and the new cluster electronics occurs in time slice 4 .

The thematic evolution map (Figure 12) shows the complex process and metamorphoses of a starting field of science to its merging or splitting with other scientific areas. Additionally, new emerging scientific sections are depicted.

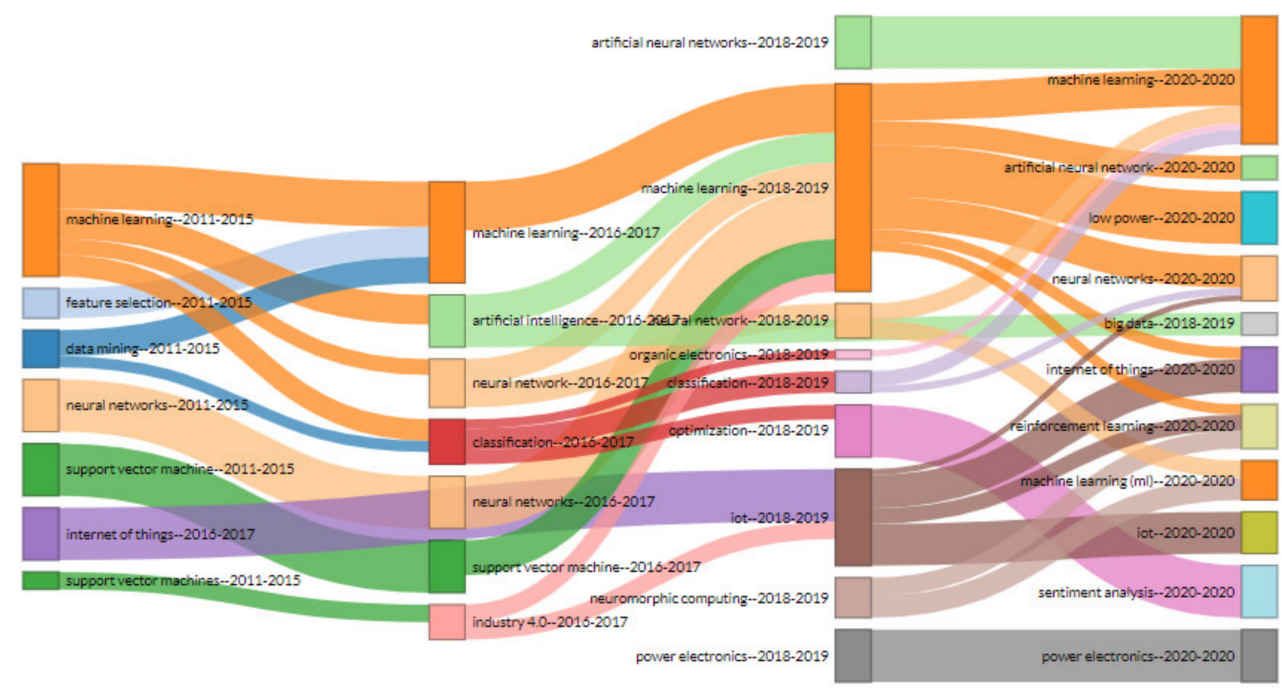

Figure 12. Thematic evolution.

\subsection{Analysis of Selected Papers}

For further analysis, the chosen journals are among the most relevant and with the highest-impact sources; another important factor for selection is their open access. Open access is the preferred format for further exploration because it enables research ideas to be widely spread among scientists regardless of their geolocation. More and more authors prefer to publish in open access journals for wide spreading of their novel and innovative solutions. Such an approach is extremely suitable for idea dissemination in emerging scientific areas, as is the case of the utilization of machine learning in electronics. Thus, the following open source journals are taken into account for investigation as the total number of reviewed scientific papers is 44:

- Journal of Physics: Conference Series (8 papers are discussed),

- MDPI Sensors (15),

- MDPI Applied Sciences (5),

- MDPI Electronics (6),

- Elektronika ir Elektrotechnika (7),

- Nature Communications (3).

In the Journal of Physics: Conference Series, 25 documents are found to satisfy the query "machine learning and electronics", from which eight are selected for examination because of their strong relevance to the researched topic.

In the first one, Arul et al. report an intelligent system for fire detection as early as possible to avoid bigger damage [16]. CCTV cameras are used for visual information gathering. The system performs further processing for the generation of a notification message. The machine learning technique is applied to compare the currently grasped visual pictures of the place with the pre-defined picture set of the same place when there is a fire.

Wei and Jia present how machine learning is used for the identification of an electromyographic signal (sEMG) for capturing the position of a robotic arm based on a muscle sensor [17]. The accuracy of six algorithms is compared: Latent Dirichlet Allocation (LDA), Decision Tree (DT), Backpropagation Neural Networks (BNN), Support Vector Machines 
(SVM), Random Forest (RF) and K-Nearest Neighbors (KNN) for recognition of four arm gestures. The chosen algorithm for experimentation is SVM.

Cheng et al. propose a method for the detection of defects in power equipment through the Faster region convolution neural network [18]. The method is characterized by high accuracy for defect detection for purposes of power inspection.

Lasbahani and Taoussi present a new approach for big data securing in real time through applying an unsupervised machine learning algorithm [19]. The anomaly detection is revealed during the big data processing.

An energy management system with the capability to control its building microgrids is presented in [20]; it generates alarm messages when equipment failure occurs. An improved SVM algorithm is used for prediction of the fault equipment based on microgrid data. The accuracy of the created model is verified through an example.

Deep machine learning is applied for the realization of an improved voice recognition system [21]. The proposed method for end-to-end speech recognition leads to simplifying the traditional complex process of speech recognition.

Machine learning is used for sentiment analysis as an improved feature selection method is applied [22]. The authors Danyang and Huimin have proven the effectiveness of this method at emotion classification through experiments.

An application of machine learning in the implementation of a social robot and its facial and expression recognition systems is presented in [23]. The experimental results prove a good accuracy of recognition and good human-robot interaction.

From the journal Sensors, the topics of 15 documents are examined below.

Nam et al. discuss contemporary technologies for touchscreens and the application of machine and deep learning for different purposes, such as: user identification through touchscreen, detection of different gestures, improvement the accuracy of the touch location recognition and correct recognition of multiple input sources [24].

An application of machine and deep learning algorithms (convolutional neural networks (CNN), kNN, SVM) for the identification of product quality is presented in [25]. The proposed learning architecture is able to determine welding defects according to extracted information from infrared pictures.

Signoretti et al. present a new algorithm called Tiny Anomaly Compressor for data compression in the infrastructure of Internet of Things [26]. It is based on machine learning techniques for intelligent tiny devices that can analyze local data in real time.

Wearable devices for monitoring a person's health when different working activities are performed, anomaly detection in their health state and possibilities for accidents reduction are discussed in [27]. The working environment is becoming safer through a combination of the capabilities of supervised and unsupervised machine learning and suitable IoT infrastructure.

Morales-Molina et al. propose an approach for IoT cyber-attack detection and protection framework driven by artificial intelligence methods [28]. Unsupervised techniques are utilized for the selection of the main characteristics of low power and Lossy Network and Dense Neural Network algorithm for precisely deciding a classification task.

Novac et al. present a framework for deep neural networks training and deployment on microcontrollers called MicroAI [29]. It is compared with embedded inference engines concerning the main characteristics, such as the power consumption and memory utilization.

Sensor-based gloves with included microphone, gyroscope and accelerometers are described by Cerro et al. to facilitate the realization of correct connections among parts in a production line [30]. This intelligent system improves the products quality and decreases its cost.

The problem of noise pollution in smart cities and its impact on human health is discussed in [31] as well as a solution in the form of a mobile embedded system that is based on a machine learning approach and geo-sensing application. Such a system gives more information about the current noise situation to the authorities. 
An electronic nose in support of a forest employee who has to recognize forest pathogens such as Pythium and Phytophthora is discussed in [32]. This application includes sensors and the data collected by them are classified through the SVM algorithm.

Rodríguez-Rodríguez et al. collect data from wearable sensors and predict the blood glucose level with the aim of finding the optimal therapy for each patient [33]. The accent of their work is how to create accurate short-term predictive models, personally driven, with minimal data volumes.

Rezaei et al. propose a core-sheath fiber strain sensor suitable for smart textile clothes for grasping the movement and for monitoring the persons' activities [34]. The received sensor signals are processed with a machine learning algorithm.

Peng and Li present a literature review regarding sensor-based radar systems with applications for short-range localization and life tracking [35]. The improved radar systems with integrated machine learning algorithms for data processing are also examined.

A new sensor for monitoring the blood pressure, based on machine learning algorithms, is introduced in [36]. Machine learning supports the recognition of values from the shape of the pulse wave. The distance change between the moving surface and the fixed electrode is measured as the change in capacity. This approach is suitable for non-invasive blood pressure monitoring, diagnosis, and treatment.

An embedded smartphone app for stand-alone usage with the possibility for evaluation of the balance and for the prevention of the fall risk of elderly people is discussed in [37]. The evaluation function is performed by a machine learning algorithm. Additionally, inertial sensors for the smartphone are used for monitoring the balance and risk of falling.

The problem for a cheaper approach to spatial tracking of unknown signals in ad hoc wireless sensor networks is solved in [38]. For this purpose, machine learning algorithms are used, which work in two phases related to modeling and tracking of the spatial signal. The sensors are presented as neurons as the signal identification is possible after calling a part of these neurons.

From the journal MDPI Applied Sciences, five scientific papers are selected for further examination.

Teo et al. use machine learning algorithms to predict the correct location of the touch on the screen of mobile devices such as tablets and smart phones [39]. These devices are constructed with precise transducers (accelerometers and microphones) and produced by signals at touch processed through the Random Forest algorithm. The created predictive model is characterized by high accuracy.

Byeon et al. analyzed 10 postures from a large volume of images with the aim of supporting elderly people when they move alone at home and to prevent some dangerous situations [40]. The recognition of postures is performed through applying convolutional neural networks.

Dineva et al. propose a new methodology for multi-label classification at the diagnosis of multiple faults occurring in electrical machines and drive systems [41]. In addition, the authors evaluate the severity of faults in noisy environments. The created multiclassification models are compared and validated through experiments.

$\mathrm{Li}$ et al. is interested in the realization of flexible system with more flexible devices (such as thin-film transistors) for usage in sensors, wearable devices and energy suppliers, including in the computation parts [42]. Therefore, they propose a new circuit architecture for the purposes of an image processing accelerator based on thin-film transistors. Image pre-processing and classification is performed in real time with good parameters regarding the energy consumption and image classification speed.

A region-based convolutional neural network ( $\mathrm{R}-\mathrm{CNN})$ is used for dent localization on a car surface that could be formed during the manufacturing process [43]. The accuracy of the dent detection is very high, which contributes to producing vehicles with high quality, because of the improved inspection process. 
Six papers from the journal MDPI Electronics are chosen as more relevant, and then they are reviewed.

The first one treats security problems as in this work an intrusion detection system for attack identification in a wireless network is proposed [44]. The system works in two stages as the created machine learning model conducts classification tasks concerning the traffic records at each stage. The model is validated and is characterized with high accuracy.

A kinetic energy harvester model for horse monitoring is presented in [45]. Accelerometer data are processed through machine learning techniques in order to identify early symptoms of health problems. For continuous data-sensing during training and sleeping sessions, different wireless technologies are applied as the key observed factor is optimal energy consumption.

Mursi et al. show one work from the area of crypto analysis as they present a method, based on neural networks, for attacking XOR Arbiter Physical unclonable functions (XPUF) (it is a hardware security primitive) [46]. XPUFs are used for the generation of a cryptographic key or for device authentication. The experimental results prove that this new method is capable of breaking the 64-bit 9-XPUF for $10 \mathrm{~min}$.

A platform for distributed parallel processing of image streams in real time, which utilizes a deep learning model for inference, is discussed in [47]. This platform manages different services in an efficient way, distributes resources and ensures large-scale image stream processing.

Jose et al. discuss a strategy for the implementation of an artificial neural network algorithm on microcontrollers that is suitable for IoT and Machine-to-Machine (M2M) applications [48].

Du et al. propose a method for feature extraction and selection for the optimization and classification of faults at a two-level three-phase pulse-width modulating rectifier [49]. Such a fault diagnosis approach based on open-circuit measurement can prevent unwished shutdown and can decrease the number of failures.

From the journal Elektronika ir Elektrotechnika, seven papers are selected and reviewed.

Sovilj-Nikic et al. use a regression tree algorithm for the creation of a predictive model about phone durations in the Serbian language [50]. The model has been developed taking into account several features that are obtained from a speech database in the Serbian language. The results from comparison of the evaluated model with models for other languages show similar findings.

A method for Alzheimer's disease diagnosis through a machine learning classification algorithm is proposed in [51]. The recorded EEG signals are bases for feature extraction and their further analysis. The received results prove that this method is a suitable alternative to well-known approaches for diagnosis.

Aoad presents a design of a microchip antenna with spiral shape, which is modeled through machine learning with the aim for its achieved accuracy to be high [52]. Three machine learning models are created, and they are compared through data taken from simulation and from measurement. The findings show that the developed small antenna operates in a wide high frequency diapason.

Du reports a new method for fault diagnosis of mine hoist that includes machine learning techniques such as SVM and genetic algorithm [53]. The proposed method is evaluated through experimental data as the detection rate of fault diagnosis is increased.

Teodorovic and Struharik present a hardware accelerator and novel algorithm for sparse decision tree induction with possible usage in embedded and edge applications, where there are several constraints concerning memory usage, storage capacity, and limited bandwidth [54]. The proposed approach is validated experimentally through standard UCI machine learning datasets and the results show a significant reduction in memory and storage usage as the accuracy remains the same.

Gradolewski et al. report a safety system for a collaborative robot that has the ability to prevent human health damage [55]. It is developed upon techniques from distributed computing, machine and deep learning, computer vision and sensing, robot motion control. The 
authors plan to improve the proposed system as the person at the workplace will be tracked all the time and the system will react only when entering the robot operational zone.

A usage of the Q-learning algorithm for control management of solar-powered environmental wireless sensor network nodes is presented in [56]. With the aim to improve the computer performance, machine learning techniques are applied.

Three papers from the Nature Communications journal are considered as relevant and they are reviewed.

Loke et al. discuss the realization of wearable devices for monitoring the physiological states of human body integrated through digital fiber in a shirt [57]. Some devices are used such as temperature sensors and memory devices as the collected data are proceeded through the neural network algorithm. This approach allows measured and stored data in a fiber to be used from algorithms to make suitable inferences in the area of the body temperature control or autonomous drag delivery.

Maurya et al. present a process for 3D printing of piezoresistive graphene sensors, which are integrated in car tire with the aim to measure the voltage waveforms during car motion [58]. In addition, a machine learning algorithm is created to evaluate the tire pressure. The authors believe that this work is an important step in the construction of smart tires for autonomous cars.

An architecture of multi-resistive synapses typical for neuromorphic computing is presented by Boybat et al. as it is designed to operate in a wide dynamic range and with high accuracy [59]. The authors achieved very good results after experimentation with memory devices used for unsupervised learning.

In summary, the findings from the performed bibliometric analysis and literature review in this section are presented through a developed conceptual framework (Figure 13). It outlines the current research areas that benefit in parallel from scientific achievements in machine learning and electronics in order to different intelligent hardware-based solutions to be created, improved or optimized. Several supervised and unsupervised machine learning techniques, algorithms for deep learning and reinforcement learning as well as evolutionary and genetic algorithms are used for the development of new methods that are capable of improving existing events, systems and processes or to propose novel solutions.

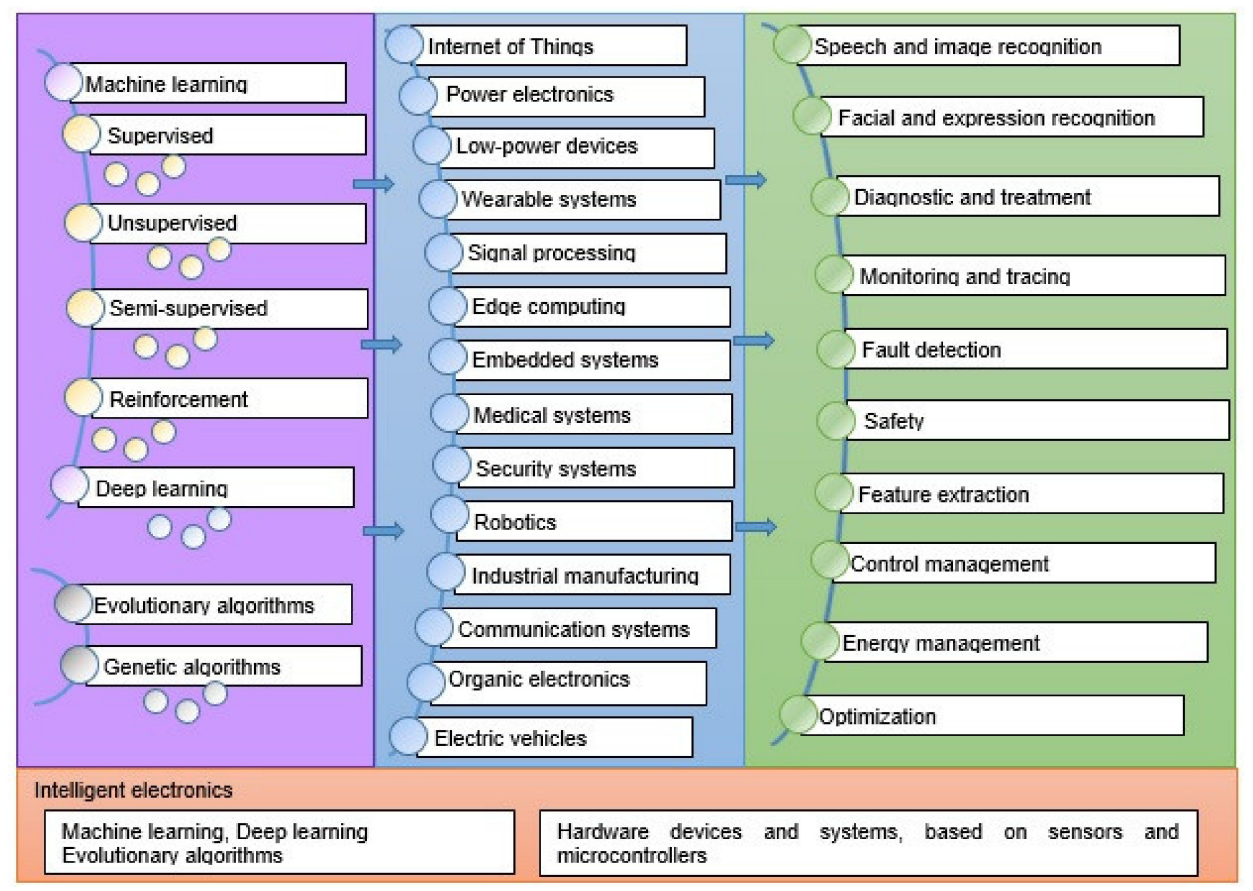

Figure 13. Conceptual framework about utilization of machine learning in electronics. 


\section{Application of Fuzzy Logic}

This section summarizes and analyses the findings obtained after applying the bibliometric method and literature review regarding the fuzzy logic applications in electronics.

For this purpose, a second query is formed, consisting of the keywords fuzzy logic and electronics, and the search is conducted in the author's keywords, abstract and title of the papers, indexed in Scopus and Web of Science.

\subsection{Scientific Production}

The returned results in the Scopus database include 1021 documents and the number of returned documents in Web of Science is 199. The indexed papers in Scopus have 2617 authors who utilize 2577 authors' keywords. The authors of single-authored documents are 36 and the authors of multi-authored documents are 2581 as the coefficient describing co-authors per documents is 3.15 and the collaboration index is 2.74 . In Web of Science, there are nine authors of single-authored documents and 618 authors of multiauthored documents; the average co-authors per documents is 3.35 and the collaboration index is 3.39. It is obvious that the bigger part of the published papers is collaborative work. Most often, the corresponding author and his co-authors are from one country as it is indicated through the Single Country Publication (SCP) parameter (Figure 14). The international collaboration when at least one co-author is from another country, measured through the Multiple Countries Publication (MCP) parameter, is not so typical for this research topic. The authors from India, China, Iran, Malaysia and Turkey have the biggest contribution according to Scopus.

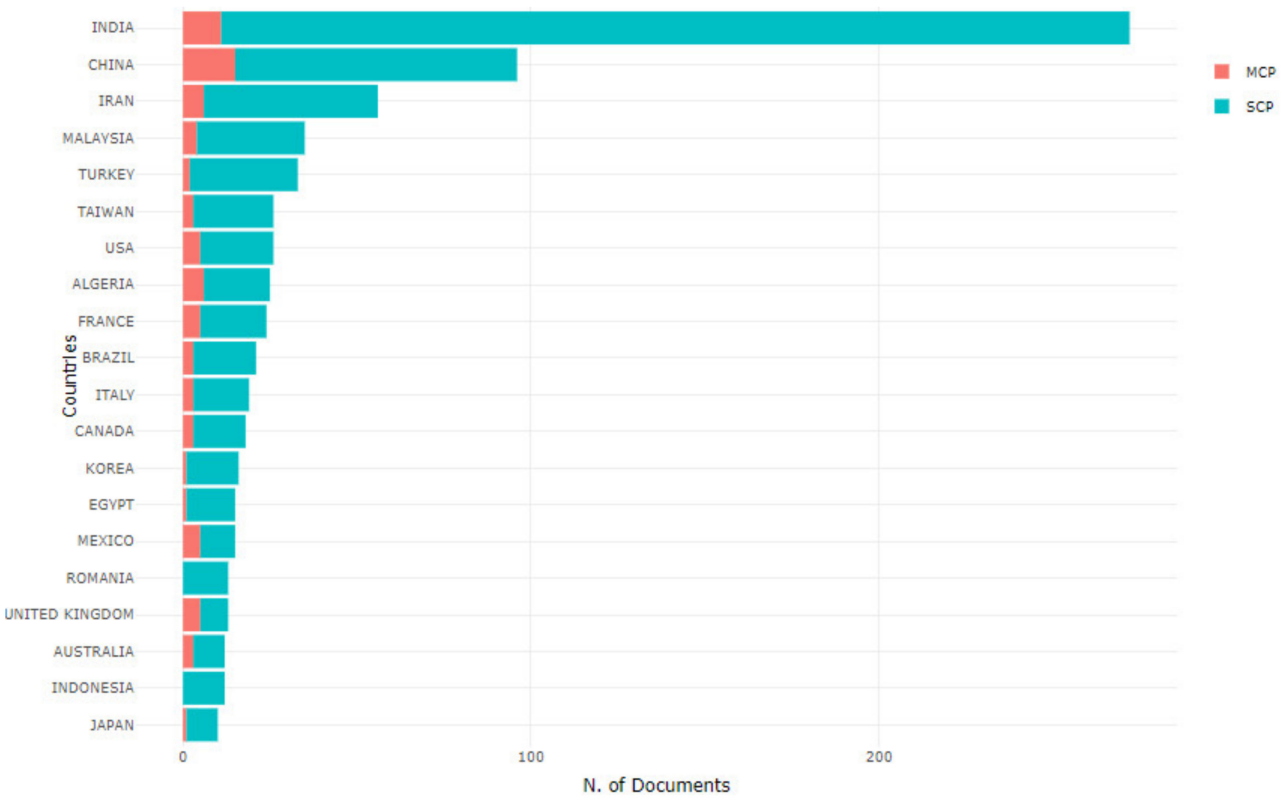

Figure 14. Corresponding author's country and collaboration according to Scopus.

The graphics of the annual scientific production is characterized with up and down points as the maximal value is obtained in 2018 year when 128 documents are included in Scopus and the minimal value is identified in 2016 year when 71 documents are indexed (Figure 15). Similar irregular graphics are constructed for the annual scientific production indexed in Web of Science. These strongly uneven graphics explain the negative values of the annual growth rate: $-1.67 \%$ for documents indexed in Scopus and $-22 \%$ for documents added in Web of Science. 


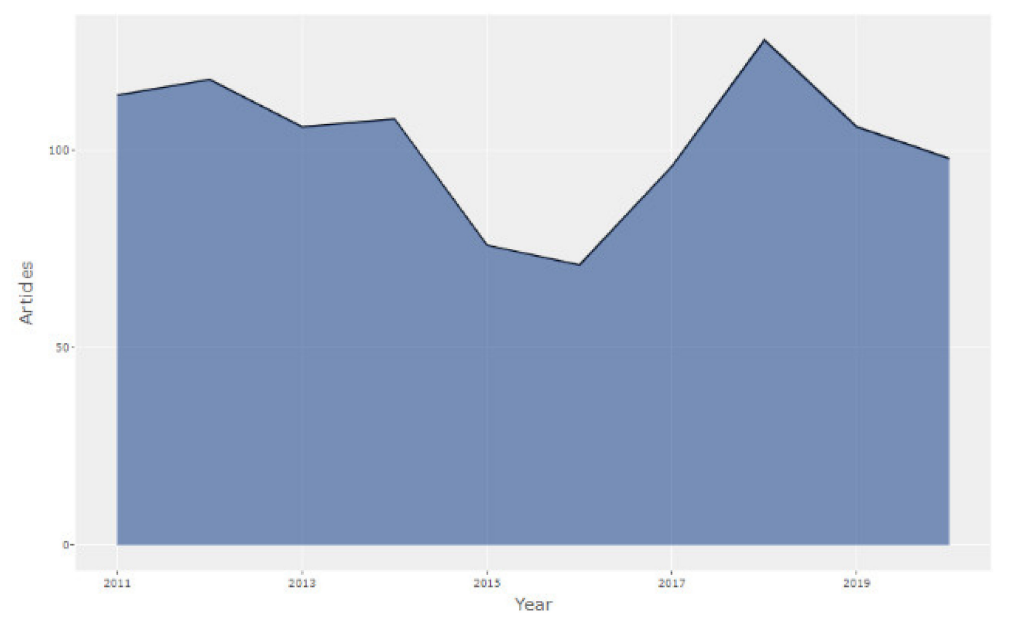

Figure 15. Annual scientific production according to Scopus.

\subsection{Characteristics of Sources}

The twenty most relevant sources with published scientific papers in the explored topic according to Scopus are presented in Figure 16. They could be categorized into two groups: proceedings of scientific forums:

- IECON Proceedings (Industrial Electronics Conference),

- INDIA International Conference on Power Electronics IICPE,

- IEEE International Symposium on Industrial Electronics,

- IEEE International Conference on Power Electronics Intelligent Control and Energy Systems ICPEICES,

and scientific journals and books:

- Applied Mechanics and Materials,

- Lecture Notes in Electrical Engineering,

- IEICE Transactions on Communications

- Advanced Materials Research,

- Procedia Engineering.
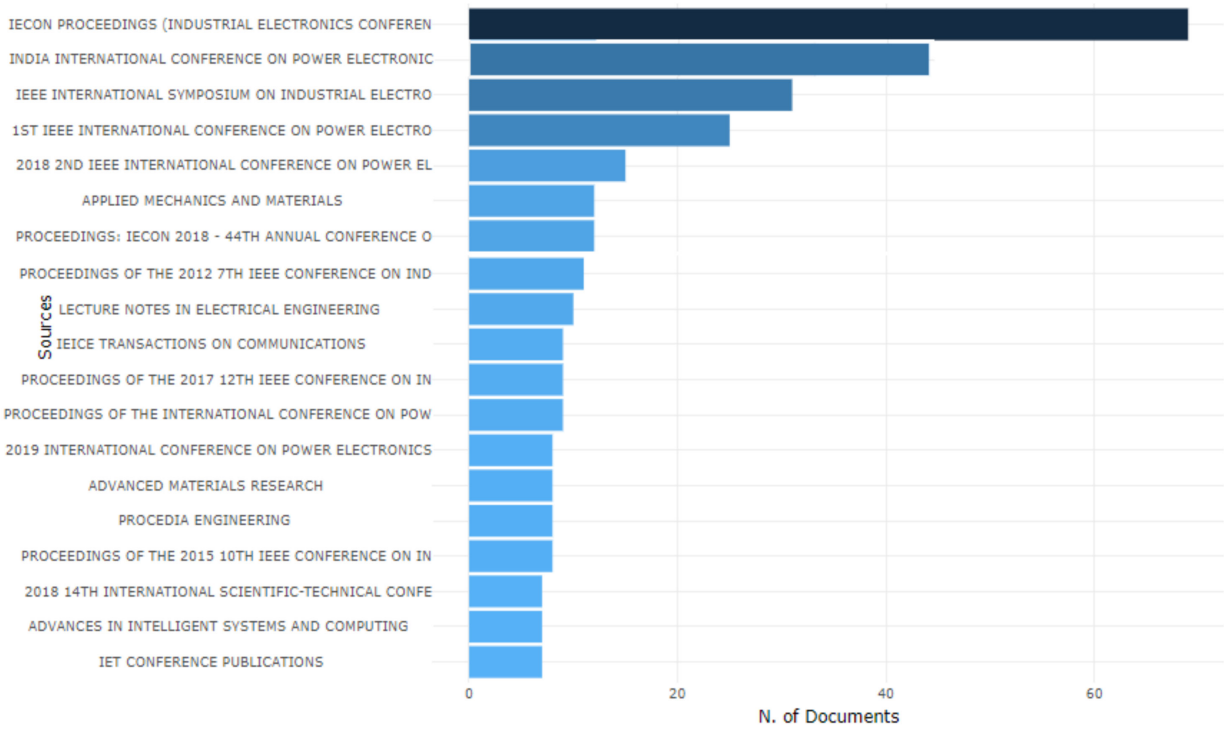

Figure 16. Most relevant sources according to Scopus.

The twenty most related sources found in Web of Science are presented in Figure 17 as they consist of mainly scientific journals such as:

- IEEE Access, 
- Energies,

- Elektronika Ir Elektrotechnika,

- Journal of Intelligent \& Fuzzy Systems,

- Applied Soft Computing.
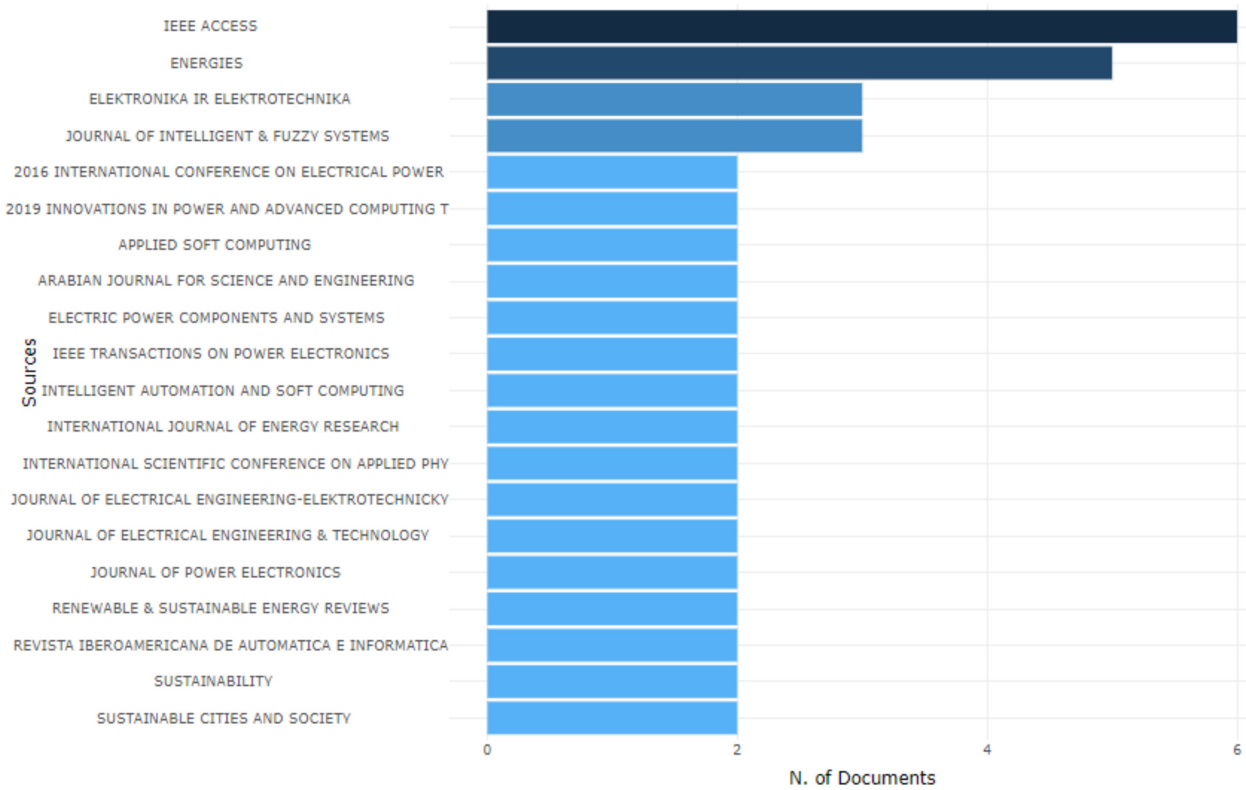

Figure 17. The most relevant sources according to Web of Science.

When the Bradford's law is applied to the publications, indexed in Scopus, then 25 sources from 466 are found to be in the first zone, which are characterized by the biggest contribution. According to Web of Science, 34 sources are in the first zone from 169.

A summarization about the sources with the highest impact (h-index) according to Scopus and Web of Science is presented in Table 4. It can be seen that the results from Scopus point out the conference proceedings as sources with the highest h-index in comparison to the results from Web of Science where the scientific journals are found to be with the highest impact.

Table 4. Sources indexed in Scopus and Web of Science with the highest h-index.

\begin{tabular}{cc}
\hline Source & h-Index \\
\hline Applied Soft Computing (Web of Science) & 143 \\
\hline IEEE Access (Web of Science) & 127 \\
\hline Energies (Web of Science) & 93 \\
\hline Procedia Engineering (Scopus) & 74 \\
\hline IECON Proceedings (Industrial Electronics Conference) (Scopus) & 71 \\
\hline IEICE Transactions on Communications (Scopus) & 56 \\
\hline ApEE International Symposium on Industrial Electronics (Scopus) & 53 \\
\hline Proceedings of the International Conference on Power Electronics and Drive Systems (Scopus) & 38 \\
\hline Electronics (Web of Science) & 36 \\
\hline Turkish Journal of Electrical Engineering and Computer Sciences (Web of Science) & 30 \\
\hline Journal of Electrical Engineering and Technology (Web of Science) & 27 \\
\hline Elektronika ir Elektrotechnika (Web of Science) & 26 \\
\hline Proceedings of the 2012 7th IEEE Conference on Industrial Electronics and Applications, ICIEA & 15 \\
\hline 2012 (Scopus) & 52 \\
\hline
\end{tabular}




\subsection{Trending Research Topics}

For purposes of conceptualization the explored scientific area, deeper analysis of the author's keywords and keywords plus is performed as the results are summarized in Tables 5 and 6 (according to Scopus). It can be noticed that more utilized keywords are related to control, different types of fuzzy controllers, converters, electric vehicles and power management.

Table 5. Authors' keywords according to Scopus.

\begin{tabular}{cc}
\hline \multicolumn{2}{c}{ Author's Keywords and Occurrences } \\
\hline fuzzy logic-279 & fuzzy logic controller-93 \\
fuzzy logic control-60 & fuzzy logic controller flc-37 \\
fuzzy control-37 & pi controller-36 \\
power quality-27 & power electronics-26 \\
mppt (maximum power point tracker)-19 & microgrid-18 \\
neural network-17 & wind turbine-17 \\
pid controller-14 & induction motor-14 \\
energy management-12 & photovoltaic-12 \\
boost converter-11 & artificial intelligence-11 \\
DC-DC converter-11 -11 & electric vehicle-11
\end{tabular}

Table 6. Keywords plus according to Scopus.

\begin{tabular}{|c|c|}
\hline \multicolumn{2}{|c|}{ Keywords Plus and Occurrences } \\
\hline fuzzy logic-904 & power electronics-371 \\
\hline controllers-328 & computer circuits-283 \\
\hline fuzzy logic controllers-261 & industrial electronics-214 \\
\hline fuzzy logic control-118 & fuzzy inference-110 \\
\hline power control-94 & DC-DC converters- 88 \\
\hline electric inverters-81 & low power electronics -71 \\
\hline algorithms-63 & power quality-54 \\
\hline neural networks-52 & photovoltaic cells -51 \\
\hline electric drives-51 & electric power transmission networks -50 \\
\hline wind power- -50 & electric machine control-49 \\
\hline
\end{tabular}

The constructed visual map about trending topics after analysis of the authors' keywords is presented on Figure 18. For 2020, the trending themes are related to the keywords: Internet of Things, fuzzy-logic controller, torque ripple (an effect in electric motors), dstatcom (it is distribution static compensator used for controlling the power quality of distribution power systems), machine learning, hybrid energy storage system.

\section{fuzzy logic}

-fuzzy logic controller

fuzzy logic control

fuzzy control

fuzzy logic controller (flc)
power electronics

${ }_{\text {. }}$ facts neural network

fuzzy controller-?

maximum power

photovoltaic energy management

.

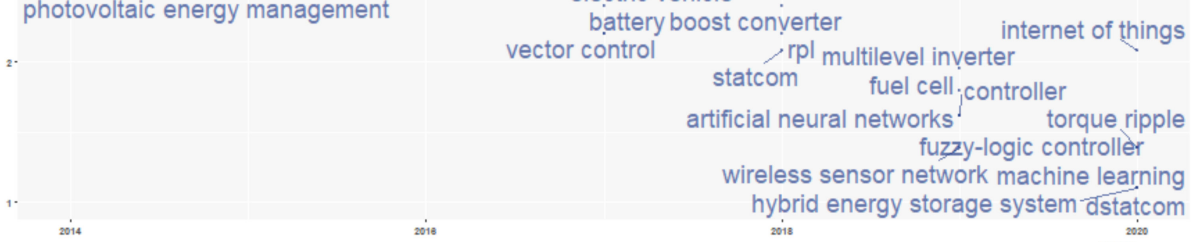

sois

Figure 18. Trending topics according to Scopus. 


\subsection{Thematic Evolution}

Figure 19 presents the created thematic map for a ten-year period according to Scopus. The "motor" clusters are wind turbine and neural network as the cluster power electronics is on the border between "motor" and "basic and transversal" themes. In the second quadrant are "highly developed and insolated" themes such as Internet of Things and fuzzifier. The clusters fuzzy sets, fault detection and electric vehicle occur in the third quadrant "emerging or declining" themes as the last mention cluster is in a central position. Among the "basic and transversal" themes are: fuzzy logic, fuzzy logic control and fuzzy logic controller. The biggest cluster is fuzzy logic that contains keywords such as: neural network, genetic algorithm, pid controller, induction motor, particle swarm optimization.

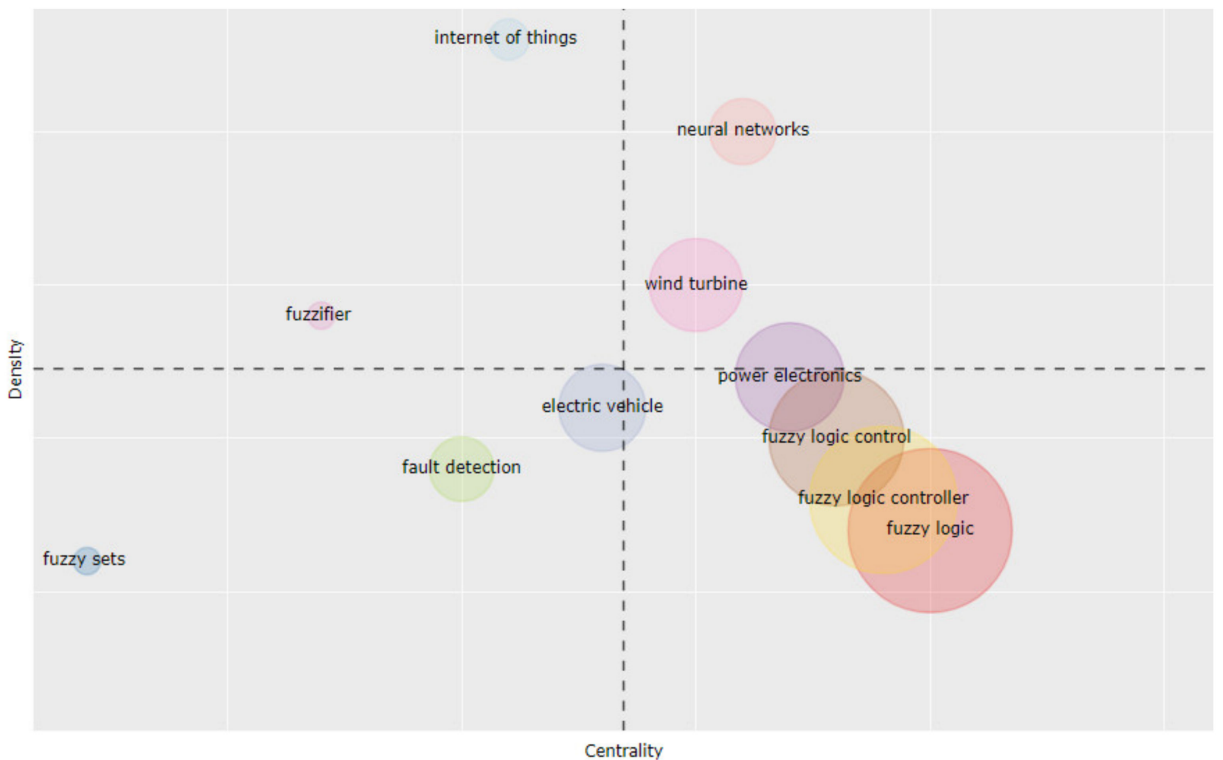

Figure 19. Thematic map based on the authors' keywords.

The thematic map, based on keywords plus, are shown on Figure 20. In comparison to the previous thematic map, based on author's keywords, the similar clusters are fuzzy logic and fuzzy logic control and the different themes are: power electronics, algorithms, power quality, DC-DC convertors.

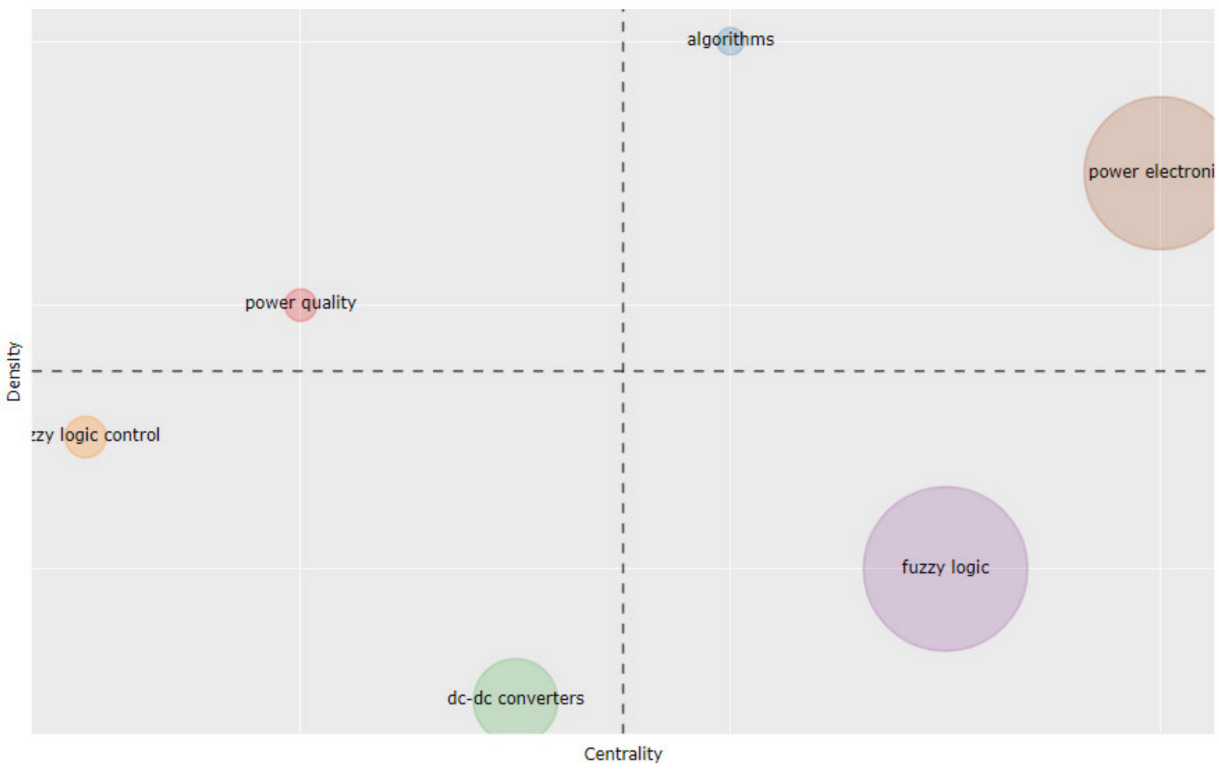

Figure 20. Thematic map, based on keywords plus. 
The thematic map based on titles of the indexed papers in Scopus is presented on Figure 21. It can be seen that the most utilized words in the title of papers are: fuzzy, motor, electronics, converter, networks, application, power, system.

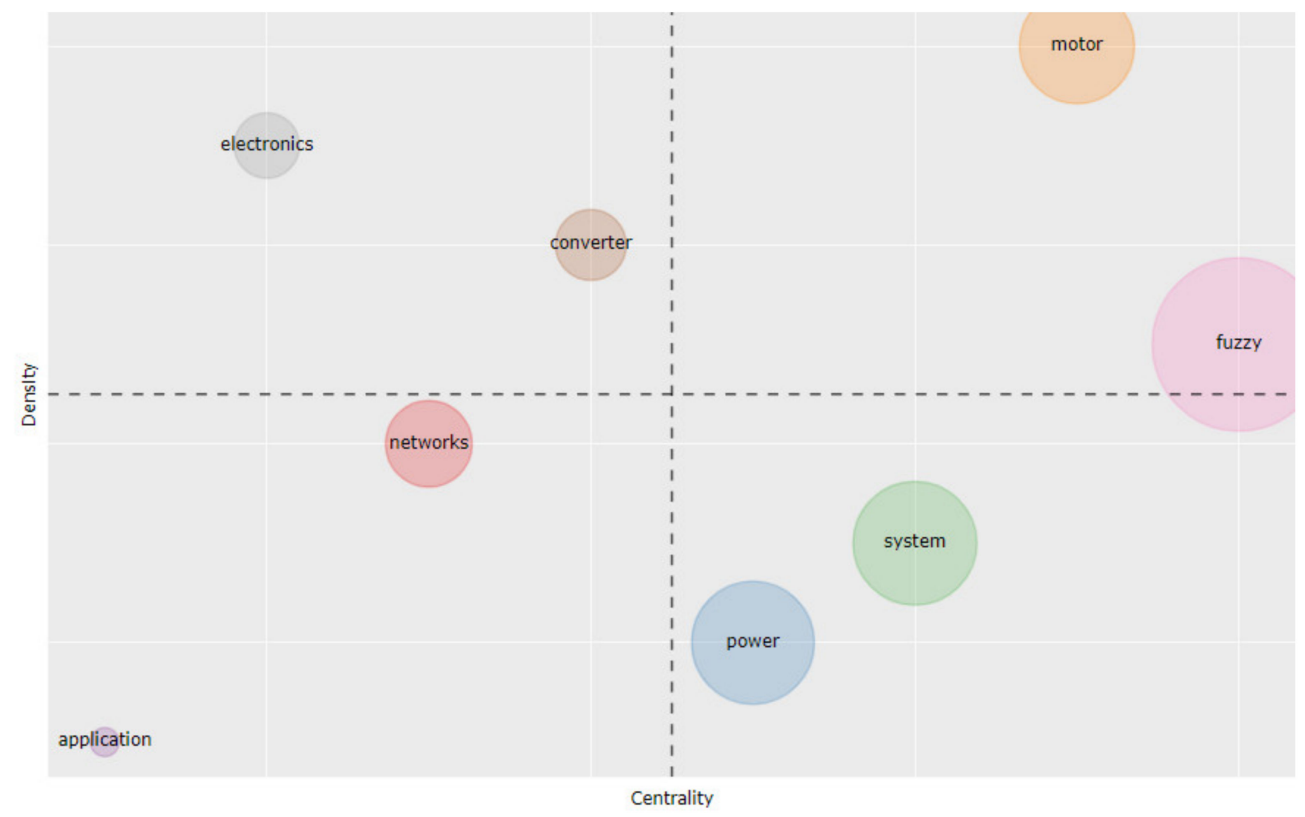

Figure 21. Thematic map based on titles.

The evolution of themes, their splitting and merging, is presented on Figure 22. This graphic is created according to the Scopus database. It can be seen that the fuzzy logic theme diverges into three branches: fuzzy logic, power electronics and fuzzy controller. At the same time, two new branches appear: fuzzy control and mppt (maximum power point tracker).

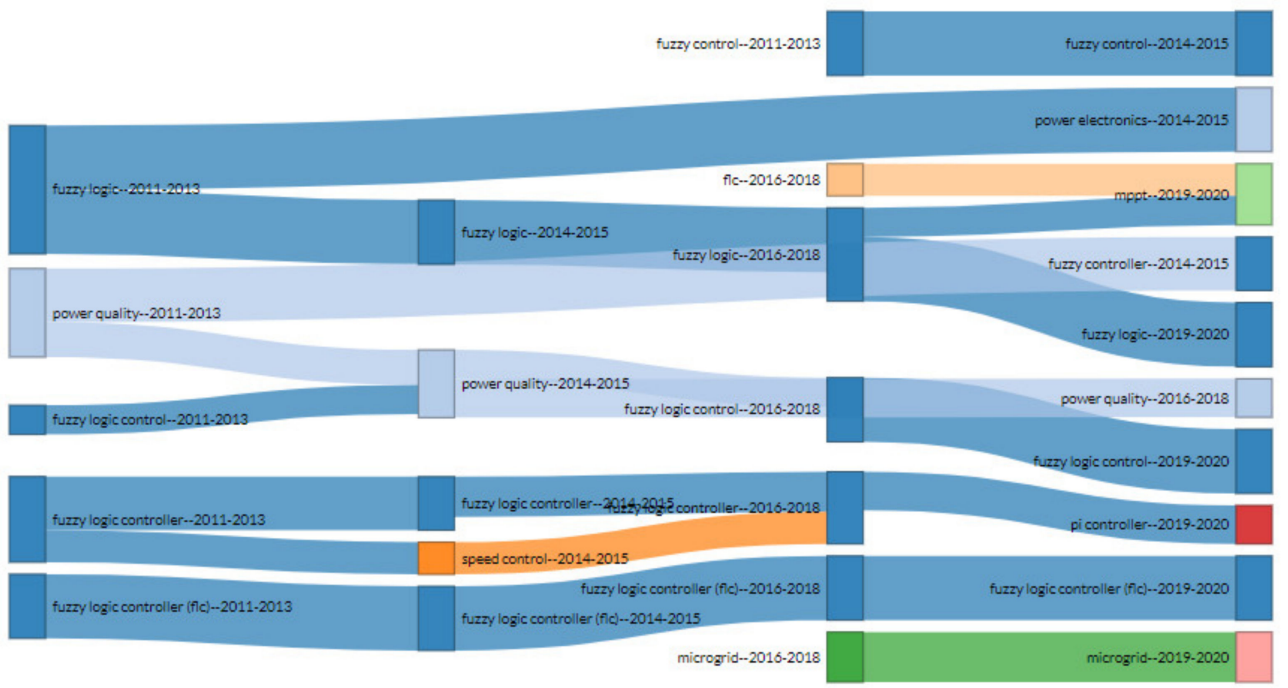

Figure 22. Thematic evolution.

In summary, fuzzy logic is a theory that finds wide applications in the realization of hardware-based systems for control, power management, monitoring and diagnostics, fault detection, prediction and optimization.

\subsection{Analysis of Selected Papers}

The following sources with open access and with the most relevant topics are selected for further exploration as 22 published scientific papers are explored:

- Procedia Engineering (7), 
- $\quad$ Energies (7),

- Elektronika ir Elektrotechnika (5) and

- Applied Soft Computing (3).

In Procedia Engineering, eight papers are found as a result of the formed query "fuzzy logic and electronics". The topics of seven papers relevant to the investigated domain are discussed.

Fuzzy logic is applied at fuzzy controller construction for DC-DC converters, which are often used in the area of the telecommunication sector and for consumer electronics purposes [60]. Some characteristics of PID (proportional-integral-derivative) controller and fuzzy logic controller are compared and the findings point out the achievement of minimum values for given parameters of fuzzy logic controller.

Fan and Zhang report for development of a fuzzy differential flatness-based controller with application in induction motor vector control system [61]. This approach leads to the improvement of the control performance.

A controller for steady-state control based on fuzzy logic and neural networks techniques is proposed in [62]. The control scheme for adaptive controllers and switch algorithm are also presented.

A model of vibration diagnostic system is created through the use of fuzzy logic aiming for better reliability at diagnostics with minimal cost to be achieved [63]. An example of such a system is presented, and it is proven that fuzzy logic is an efficient method for the development of monitoring and diagnostic systems.

Ualikhan and Josif discuss the developed algorithm for the control of a leakage current protection system that is adaptive to voltage oscillations of controllable network and suitable for application in the mining industry [64]. Fuzzy logic is used in the design of fuzzy controller, which is a part of an isolated neutral system. The adaptive protection devices are desirable for electric equipment protection that consists of electric drivers, which are frequency regulated.

Kumar and Ashok present a fuzzy logic model for monitoring a solid-state welding process [65]. The experiments are performed with different parameters of the friction stir welding process as the fuzzy model is used for prediction of the weld strength and nugget hardness of the alloy. The model accuracy is evaluated through experimental results.

Zhong et al. discuss the evaluation of the previously developed a weight-based fuzzy logic control algorithm with applications in the simultaneous control of indoor humidity and temperature through an air conditioning system [66]. The prepared model for simulation includes several parts, including a controller that operates according to the described algorithm.

From the journal Energies, seven papers are selected for further examination.

The aim of the first one is an analysis to be performed regarding the dynamic stability of wind power flow in a wind-based energy storage system [67]. For maintaining this stability, a control algorithm is developed. The control is realized in two variants through fuzzy logic controller and PID controller and their functionality is compared. The simulation results show that the fuzzy logic controller is characterized with better performance than the PID controller in solving this analytical task.

Fuzzy logic control is used in parallel with control of grid-feeding mode (VOC) in order to solve the voltage dynamic problem in a PV (photovoltaic)-interconnected distribution network, which problem is caused by worse weather conditions [68]. In this work, a DC scheme is proposed for fault detection based on fuzzy logic instead of the usage of an AC scheme. This approach allows the mitigation of the voltage dynamics.

Napole et al. design a fuzzy logic controller and airflow reference generator for oscillating water column systems aiming for the turbine speed to be regulated in a more effective way and efficiency of the system at whole to be improved [69]. The simulation results prove the enhanced system performance and stalling avoidance.

Tracker fuzzy controllers are utilized for DC voltage regulation in a combined system that consists of PV panels, wind turbines, converters, and energy storage [70]. The purpose 
of this work is to present a control strategy for the efficient management of the produced energy and management of the overall performance of the hybrid energy system.

A push-pull converter that works according to a fuzzy logic-based maximum power point tracking algorithm is used in an isolated PV system aiming for the output power of this system to be optimized [71]. The results from simulation prove the suitability of the utilized fuzzy logic algorithms and also the findings point out that the total harmonic distortions are reduced.

A controller based on fuzzy logic is used to enhance the performance of the antilock braking system in vehicles when the environmental conditions are critical [72]. The simulation results show better vehicle maneuverability at high speed and at different road surfaces when fuzzy logic is applied in comparison to the conventional anti-lock braking system.

An energy management system, which is capable to make longer the battery usage in electric vehicles, is proposed in [73]. It is constructed through design of fuzzy logic controller. An analysis that compares the conventional and presented energy management system is conducted and it shows the advantages of the proposed solution related to decreased power losses and reduced stress of the battery.

Five papers from the journal Elektronika ir Elektrotechnika are selected for examination.

Aydogmus develops an algorithm based on fuzzy logic that is used in programmable logic controller for liquid level control system [74]. The created fuzzy controller is tested and its workability and contribution to the improved performance of the control system is proved.

A fuzzy logic controller is designed with the aim to control a soft-switching DCDC converter, which is characterized by nonlinearity [75]. The simulations outline the improved workability of the converter when a fuzzy logic controller is used in comparison to the utilization of a classical PI controller.

$\mathrm{Wu}$ et al. propose a novel fuzzy logic controller in order to achieve a higher performance from the drive system of electric vehicles [76]. The drive and communication systems are implemented and tested for a $50 \mathrm{~kW}$ motor prototype. The comparison between the novel and conventional fuzzy logic controllers shows that the novel approach possesses better characteristics.

A fuzzy logic controller is used in a home energy management system as the main purpose is for the energy consumption and cost to be decreased [77]. The proposed system can analyze the energy usage during peak and non-peak hours, and it is proved that the energy is managed in an efficient way.

A comparison between fuzzy and genetic PI controllers is carried out in [78], which is used for speed motor control. The findings point out that the genetic controller has a smaller settling time and steady-state error, but it is less sensitive to variations of some parameters.

From the journal Applied Soft Computing, three papers are found to have strong relevance to the research domain; in the next paragraphs, they are reviewed.

Su et al. discuss the utilization of two fuzzy logic algorithms - average and adaptivesuitable for computing and monitoring the temperature in wireless sensor networks [79]. Comparison between these methods is performed and the results show that the adaptive algorithm has better performance.

A type-2 fuzzy logic system with applications in a restructure power system for control of the load frequency is presented in [80]. The type-2 fuzzy controller is analyzed and showed better performance in comparison to the type- 1 fuzzy controller and the PID controller.

Rastelli and Peñas present a fuzzy logic system with applications in autonomous vehicles in support of steering control [81]. The experiment with the created prototype shows sufficient results at different speeds and maneuvers.

This detailed analysis shows the usage of fuzzy logic mainly for the development of control systems and, in rare cases, for implementation in systems for monitoring, diagnostics and fault detection. 


\section{Conclusions and Future Work}

This paper presents an analysis and review of papers published and indexed in Scopus and Web of Science that discuss the application of machine learning and fuzzy logic techniques in electronics. The defined aim is the conceptual vision to be outlined and the achieved knowledge in the investigated domain to be mapped. In this way, the trending topics and research directions are derived. In order for this analysis to be deeper and more complete, a combination of a bibliometric approach and detailed paper review is carried out. The findings describe the scientific area during the last 10 years with a growing curve concerning the machine learning adoption for solving a wide variety of problems in electronics and with a wavering curve for fuzzy logic utilization. It can be said that machine learning is employed in almost all electronics research fields for the development and improvement of recognition systems, preventive and safety systems, systems for diagnostics and treatment, for monitoring and tracing systems, for feature selection and extraction, fault detection, energy and control management systems and optimization. At the same time, fuzzy logic is mainly used for the implementation and optimization of control systems.

Among the trending research topics, developments for the purposes of Internet of Things, security systems, medical equipment, robotics, industrial manufacturing, embedded systems, monitoring and control systems are found.

The thematic evolution reveals the increasing role of machine learning algorithms for solving different problems in the domain of electronics. The bibliometric analysis shows that the content of the machine learning cluster is dynamically changed during the observed time period, remaining in a stable position on the map. This cluster is in continuous evolvement; through the increased interest of researchers, the existing algorithms have improved and novel techniques have been developed. Algorithms for classification are formed in a separate cluster that points out their importance. Algorithms for reinforcement learning also have a significant role that is presented through their placement in a different cluster. Several clusters of artificial neural networks have appeared during the whole investigated time period as their leading role is still actual. They are under progressive development, and it is dictated by their capability for solving complex real problems. The position of genetic and evolutionary algorithms is presented on the thematic map in the form of a small cluster only in the first time slice (2011-2014). During other time slices, they are absorbed by other clusters. The performed detailed literature analysis proves the important role of machine learning for the electronics domain, describing the exact application of concrete algorithms such as: SVM, tree-based algorithms, KNN and others, as well as the utilization of several architectures of artificial neural networks. Evolutionary and genetic algorithms are also mentioned in scientific publications as suitable approaches for specific problems.

The exploration regarding the thematic evolution of fuzzy logic reveals some directions for evolvement that is presented with formed clusters on the map, such as: fuzzy logic control and fuzzy logic controller. Sometimes, the combination of fuzzy logic and neural networks techniques is the preferred approach for the examination, optimization or implementation of a new method, methodology or application. For 2020, the trending themes are connected to the keywords: Internet of Things, fuzzy-logic controller, torque ripple, dstatcom, machine learning, hybrid energy storage system. A detailed literature review confirms the obtained findings through applied bibliometric approach, showing the workability of concrete intelligent systems.

This extensive research outlines how much work is carried out, but also draws problems that could be resolved through applying machine learning and fuzzy logic. Our intention for future research is related to the following issues: (1) further exploration of the possibilities of machine learning algorithms for the facilitation of the analysis, design, measurement, testing and diagnostics of electronic modules, devices and systems and their production process to achieve an appropriate level of intelligence in created hardware and software solutions; (2) development of methods/methodologies/algorithms for conduc- 
tance of analytical, predictive and optimization tasks in support of designers, test-engineers and production process experts; (3) development of software modules in assistance of the evaluation procedures regarding the application of machine learning and fuzzy logic.

Author Contributions: Conceptualization, M.I. and P.P.; methodology, M.I.; software, N.P.; validation, M.I., P.P. and N.P.; formal analysis, M.I.; investigation, M.I., P.P. and N.P.; resources, M.I.; writing-original draft preparation, M.I.; writing-review and editing, M.I. and P.P.; visualization, N.P.; funding acquisition, M.I. All authors have read and agreed to the published version of the manuscript.

Funding: This research is supported by Bulgarian National Science Fund in the scope of the project "Exploration the application of statistics and machine learning in electronics" under contract number КП-06-H42/1.

Conflicts of Interest: The authors declare no conflict of interest.

\section{References}

1. Sarker, I.H. Machine Learning: Algorithms, Real-World Applications and Research Directions. SN Comput. Sci. 2021, 2, 160. [CrossRef] [PubMed]

2. L'Heureux, A.; Grolinger, K.; ElYamany, H.F.; Capretz, M.A.M. Machine Learning With Big Data: Challenges and Approaches. IEEE Access 2017, 5, 7776-7797. [CrossRef]

3. Amornsamankul, S.; Pimpunchat, B.; Triampo, W.; Charoenpong, J.; Nuttavut, N. A Comparison of Machine Learning Algorithms and Their Applications. Int. J. Simul. Syst. Sci. Technol. 2019, 19, 20. [CrossRef]

4. Shrestha, A.; Mahmood, A. Review of Deep Learning Algorithms and Architectures. IEEE Access 2019, 7, 53040-53065. [CrossRef]

5. Lv, S.; Kim, H.; Zheng, B.; Jin, H. A Review of Data Mining with Big Data towards Its Applications in the Electronics Industry. Appl. Sci. 2018, 7, 582. [CrossRef]

6. Elfadel, I.M.; Boning, D.S.; Li, X. (Eds.) Machine Learning in VLSI Computer-Aided Design; Springer International Publishing: Berlin/Heidelberg, Germany, 2019; ISBN 978-3-030-04666-8.

7. Hensel, S.; Marinov, M.B.; Schmitt, M. Object Detection and Mapping with Unmanned Aerial Vehicles Using Convolutional Neural Networks. In Future Access Enablers for Ubiquitous and Intelligent Infrastructures; Perakovic, D., Knapcikova, L., Eds.; FABULOUS, 2021; Lecture Notes of the Institute for Computer Sciences, Social Informatics and Telecommunications Engineering; Springer: Cham, Switzerland, 2021; Volume 382. [CrossRef]

8. Hensel, S.; Marinov, M.B.; Schwilk, T.; Nikolov, D. Application of Gaussian Process Estimation for Magnetic Field Mapping. In Future Access Enablers for Ubiquitous and Intelligent Infrastructures; Perakovic, D., Knapcikova, L., Eds.; FABULOUS, 2021; Lecture Notes of the Institute for Computer Sciences, Social Informatics and Telecommunications Engineering; Springer: Cham, Switzerland, 2021; Volume 382. [CrossRef]

9. Hu, Z.; Han, T.; Sun, P.; Pan, J.; Manocha, D. 3D Deformable Object Manipulation using Deep Neural Networks. IEEE Robot. Autom. Lett. 2019, 4, 4255-4261. [CrossRef]

10. Ross, T.J. Fuzzy Logic with Engineering Applications, 4th ed.; Wiley-Blackwell: Hoboken, NJ, USA, 2016; ISBN 978-1-119-23586-6.

11. Dumitrescu, C.; Ciotirnae, P.; Vizitiu, C. Fuzzy Logic for Intelligent Control System Using Soft Computing Applications. Sensors 2021, 21, 2617. [CrossRef]

12. Rialti, R.; Marzi, G.; Ciappei, C.; Busso, D. Big data and dynamic capabilities: A bibliometric analysis and systematic literature review. Manag. Decis. 2019, 57, 2052-2068. [CrossRef]

13. Muritala, B.A.; Sánchez-Rebull, M.-V.; Hernández-Lara, A.-B. A Bibliometric Analysis of Online Reviews Research in Tourism and Hospitality. Sustainability 2020, 12, 9977. [CrossRef]

14. Aria, M.; Cuccurullo, C. Bibliometrix: An R-tool for comprehensive science mapping analysis. J. Informetr. 2017, 11, 959-975. [CrossRef]

15. Perianes-Rodriguez, A.; Waltman, L.; van Eck, N.J. Constructing bibliometric networks: A comparison between full and fractional counting. J. Informetr. 2016, 10, 1178-1195. [CrossRef]

16. Arul, A.; Prakaash, R.S.H.; Raja, R.G.; Nandhalal, V.; Kumar, N.S. Fire Detection System Using Machine Learning. J. Phys. Conf. Ser. 2021, 1916, 012209. [CrossRef]

17. Wei, Y.; Jia, D. Research on Robotic Arm Movement Grasping System Based on MYO. J. Phys. Conf. Ser. 2021, 1754, 012173. [CrossRef]

18. Cheng, Y.; Xia, L.; Yan, B.; Chen, J.; Hu, D.; Zhu, L. A Defect Detection Method Based on Faster RCNN for Power Equipment. J. Phys. Conf. Ser. 2021, 1754, 012025. [CrossRef]

19. Lasbahani, A.; Taoussi, C. A new unsupervised learning-based process for extraction of knowledge's and improving anomalies detection. J. Phys. Conf. Ser. 2021, 1743, 012024. [CrossRef]

20. Yuan, H.; Zhang, Z.; Yuan, P.; Wang, S.; Wang, L.; Yuan, Y. A microgrid alarm processing method based on equipment fault prediction and improved support vector machine learning. Phys. Conf. Ser. 2020, 1639, 012041. [CrossRef]

21. Wang, S.; Li, G. Overview of end-to-end speech recognition. J. Phys. Conf. Ser. 2019, 1187, 052068. [CrossRef] 
22. Danyang, L.; Huimin, F. Research and Improvement of CHI Feature Selection in Sentiment Analysis. J. Phys. Conf. Ser. 2019, 1187, 052022. [CrossRef]

23. Sanjaya, W.M.; Anggraeni, D.; Juwardi, A.; Munawwaroh, M. Design of Real Time Facial Tracking and Expression Recognition for Human-Robot Interaction. J. Phys. Conf. Ser. 2018, 1090, 012044. [CrossRef]

24. Nam, H.; Seol, K.H.; Lee, J.; Cho, H.; Jung, S.W. Review of Capacitive Touchscreen Technologies: Overview, Research Trends, and Machine Learning Approaches. Sensors 2021, 21, 4776. [CrossRef]

25. Knaak, C.; von Eßen, J.; Kröger, M.; Schulze, F.; Abels, P.; Gillner, A. A Spatio-Temporal Ensemble Deep Learning Architecture for Real-Time Defect Detection during Laser Welding on Low Power Embedded Computing Boards. Sensors 2021, $21,4205$. [CrossRef] [PubMed]

26. Signoretti, G.; Silva, M.; Andrade, P.; Silva, I.; Sisinni, E.; Ferrari, P. An Evolving TinyML Compression Algorithm for IoT Environments Based on Data Eccentricity. Sensors 2021, 21, 4153. [CrossRef] [PubMed]

27. Márquez-Sánchez, S.; Campero-Jurado, I.; Robles-Camarillo, D.; Rodríguez, S.; Corchado-Rodríguez, J.M. Besafe b2.0 smart multisensory platform for safety in workplaces. Sensors 2021, 21, 3372. [CrossRef] [PubMed]

28. Morales-Molina, C.D.; Hernandez-Suarez, A.; Sanchez-Perez, G.; Toscano-Medina, L.K.; Perez-Meana, H.; Olivares-Mercado, J.; Portillo-Portillo, J.; Sanchez, V.; Garcia-Villalba, L.J. A Dense Neural Network Approach for Detecting Clone ID Attacks on the RPL Protocol of the IoT. Sensors 2021, 21, 3173. [CrossRef] [PubMed]

29. Novac, P.-E.; Hacene, G.B.; Pegatoquet, A.; Miramond, B.; Gripon, V. Quantization and Deployment of Deep Neural Networks on Microcontrollers. Sensors 2021, 21, 2984. [CrossRef]

30. Cerro, I.; Latasa, I.; Guerra, C.; Pagola, P.; Bujanda, B.; Astrain, J.J. Smart System with Artificial Intelligence for Sensory Gloves. Sensors 2021, 21, 1849. [CrossRef]

31. Hernandez-Jayo, U.; Goñi, A. ZARATAMAP: Noise Characterization in the Scope of a Smart City through a Low Cost and Mobile Electronic Embedded System. Sensors 2021, 21, 1707. [CrossRef]

32. Borowik, P.; Adamowicz, L.; Tarakowski, R.; Wacławik, P.; Oszako, T.; Ślusarski, S.; Tkaczyk, M. Application of a Low-Cost Electronic Nose for Differentiation between Pathogenic Oomycetes Pythium intermedium and Phytophthora plurivora. Sensors 2021, 21, 1326. [CrossRef]

33. Rodríguez-Rodríguez, I.; Chatzigiannakis, I.; Rodríguez, J.-V.; Maranghi, M.; Gentili, M.; Zamora-Izquierdo, M.-Á. Utility of Big Data in Predicting Short-Term Blood Glucose Levels in Type 1 Diabetes Mellitus through Machine Learning Techniques. Sensors 2019, 19, 4482. [CrossRef]

34. Rezaei, A.; Cuthbert, T.J.; Gholami, M.; Menon, C. Application-Based Production and Testing of a Core-Sheath Fiber Strain Sensor for Wearable Electronics: Feasibility Study of Using the Sensors in Measuring Tri-Axial Trunk Motion Angles. Sensors 2019, 19, 4288. [CrossRef]

35. Peng, Z.; Li, C. Portable Microwave Radar Systems for Short-Range Localization and Life Tracking: A Review. Sensors 2019, 19, 1136. [CrossRef]

36. Quan, X.; Liu, J.; Roxlo, T.; Siddharth, S.; Leong, W.; Muir, A.; Cheong, S.-M.; Rao, A. Advances in Non-Invasive Blood Pressure Monitoring. Sensors 2021, 21, 4273. [CrossRef]

37. Greene, B.R.; McManus, K.; Ader, L.G.M.; Caulfield, B. Unsupervised Assessment of Balance and Falls Risk Using a Smartphone and Machine Learning. Sensors 2021, 21, 4770. [CrossRef] [PubMed]

38. Alasti, H. Communication-Efficient Tracking of Unknown, Spatially Correlated Signals in Ad-Hoc Wireless Sensor Networks: Two Machine Learning Approaches. Sensors 2021, 21, 5175. [CrossRef] [PubMed]

39. Teo, K.R.; Balamurali, B.T.; Zhou, J.; Chen, J.-M. Categorizing Touch-Input Locations from Touchscreen Device Interfaces via On-Board Mechano-Acoustic Transducers. Appl. Sci. 2021, 11, 4834. [CrossRef]

40. Byeon, Y.-H.; Lee, J.-Y.; Kim, D.-H.; Kwak, K.-C. Posture Recognition Using Ensemble Deep Models under Various Home Environments. Appl. Sci. 2020, 10, 1287. [CrossRef]

41. Dineva, A.; Mosavi, A.; Gyimesi, M.; Vajda, I.; Nabipour, N.; Rabczuk, T. Fault Diagnosis of Rotating Electrical Machines Using Multi-Label Classification. Appl. Sci. 2019, 9, 5086. [CrossRef]

42. Li, Q.; Liu, Z.; Qiao, F.; Wei, Q.; Yang, H. Could We Realize the Fully Flexible System by Real-Time Computing with Thin-Film Transistors? Appl. Sci. 2017, 7, 1224. [CrossRef]

43. Park, S.H.; Tjolleng, A.; Chang, J.; Cha, M.; Park, J.; Jung, K. Detecting and Localizing Dents on Vehicle Bodies Using Region-Based Convolutional Neural Network. Appl. Sci. 2020, 10, 1250. [CrossRef]

44. Reyes, A.A.; Vaca, F.D.; Aguayo, G.A.C.; Niyaz, Q.; Devabhaktuni, V. A Machine Learning Based Two-Stage Wi-Fi Network Intrusion Detection System. Electronics 2020, 9, 1689. [CrossRef]

45. Van Herbruggen, B.; Fontaine, J.; Eerdekens, A.; Deruyck, M.; Joseph, W.; de Poorter, E. Feasibility of Wireless Horse Monitoring Using a Kinetic Energy Harvester Model. Electronics 2020, 9, 1730. [CrossRef]

46. Mursi, K.T.; Thapaliya, B.; Zhuang, Y.; Aseeri, A.O.; Alkatheiri, M.S. A Fast Deep Learning Method for Security Vulnerability Study of XOR PUFs. Electronics 2020, 9, 1715. [CrossRef]

47. Kim, Y.-K.; Kim, Y. DiPLIP: Distributed Parallel Processing Platform for Stream Image Processing Based on Deep Learning Model Inference. Electronics 2020, 9, 1664. [CrossRef]

48. Guimarães, C.J.B.V.; Fernandes, M.A.C. Real-time Neural Networks Implementation Proposal for Microcontrollers. Electronics 2020, 9, 1597. [CrossRef] 
49. Du, B.; He, Y.; Zhang, Y. Open-Circuit Fault Diagnosis of Three-Phase PWM Rectifier Using Beetle Antennae Search Algorithm Optimized Deep Belief Network. Electronics 2020, 9, 1570. [CrossRef]

50. Sovilj-Nikic, S.; Delic, V.; Sovilj-Nikic, I.; Markovic, M. Tree-based Phone Duration Modelling of the Serbian Language. Elektron. Elektrotech. 2014, 20, 77-82. [CrossRef]

51. Podgorelec, V. Analyzing EEG Signals with Machine Learning for Diagnosing Alzheimer's Disease. Elektron. Elektrotech. 2012, 18, 61-64. [CrossRef]

52. Aoad, A. Design and Manufacture of a Multiband Rectangular Spiral-Shaped Microstrip Antenna Using EM-Driven and Machine Learning. Elektron. Elektrotech. 2021, 27, 29-40. [CrossRef]

53. Du, S. A New Method for Fault Diagnosis of Mine Hoist based on Manifold Learning and Genetic Algorithm Optimized Support Vector Machine. Elektron. Elektrotech. 2012, 123, 99-102. [CrossRef]

54. Teodorovic, P.; Struharik, R. Hardware Acceleration of Sparse Oblique Decision Trees for Edge Computing. Elektron. Elektrotech. 2019, 25, 18-24. [CrossRef]

55. Gradolewski, D.; Maslowski, D.; Dziak, D.; Jachimczyk, B.; Mundlamuri, S.T.; Prakash, C.G.; Kulesza, W.J. A Distributed Computing Real-Time Safety System of Collaborative Robot. Elektron. Elektrotech. 2020, 26, 4-14. [CrossRef]

56. Prauzek, M.; Konecny, J. Optimizing of Q-Learning Day/Night Energy Strategy for Solar Harvesting Environmental Wireless Sensor Networks Nodes. Elektron. Elektrotech. 2021, 27, 50-56. [CrossRef]

57. Loke, G.; Khudiyev, T.; Wang, B.; Fu, S.; Payra, S.; Shaoul, Y.; Fung, J.; Chatziveroglou, I.; Chou, P.-W.; Chinn, I.; et al. Digital electronics in fibres enable fabric-based machine-learning inference. Nat. Commun. 2021, 12, 3317. [CrossRef] [PubMed]

58. Maurya, D.; Khaleghian, S.; Sriramdas, R.; Kumar, P.; Kishore, R.A.; Kang, M.G.; Kumar, V.; Song, H.-C.; Lee, S.-Y.; Yan, Y.; et al. 3D printed graphene-based self-powered strain sensors for smart tires in autonomous vehicles. Nat. Commun. 2018, 11, 5392. [CrossRef] [PubMed]

59. Boybat, I.; Le Gallo, M.; Nandakumar, S.R.; Moraitis, T.; Parnell, T.P.; Tuma, T.; Rajendran, B.; Leblebici, Y.; Sebastian, A.; Eleftheriou, E. Neuromorphic computing with multi-memristive synapses. Nat. Commun. 2018, 9, 2514. [CrossRef] [PubMed]

60. Lindiya, A.; Palani, S. Iyyappan, Controllers for DC-DC Synchronous Buck Converter. Procedia Eng. 2012, 38, 2679-2693. [CrossRef]

61. Fan, L.; Zhang, L. Fuzzy based flatness control of an induction motor. Procedia Eng. 2011, 23, 72-76. [CrossRef]

62. Xu, K.; Zhang, G.; Xu, Y. Adjustment Strategy for Dynamic Tracking Neuro-Fuzzy Controller. Procedia Eng. 2011, 23, 29-33. [CrossRef]

63. Kostyukov, V.N.; Zaytsev, A.V. Using Adaptive Algorithms Based of Fuzzy Logic in Vibration Diagnostic Systems. Procedia Eng. 2016, 152, 482-486. [CrossRef]

64. Ualikhan, I.; Josif, B. Development of Control Algorithm for Adaptive Leakage Current Protection Devices' using Fuzzy Logic. Procedia Eng. 2015, 25, 666-671. [CrossRef]

65. Kumar, S.S.; Ashok, S.D. Development of Acoustic Emission and Motor Current Based Fuzzy Logic Model for Monitoring Weld Strength and Nugget Hardness of FSW Joints. Procedia Eng. 2014, 97, 909-917. [CrossRef]

66. Zhong, Z.; Xu, X.; Zhang, X.; Huang, Z. Simulation Based Control Performance Evaluation of a Novel Fuzzy Logic Control Algorithm for Simultaneously Controlling Indoor Air Temperature and Humidity Using a Direct Expansion (DX) Air-conditioning (A/C) System. Procedia Eng. 2017, 205, 1792-1799. [CrossRef]

67. Rahman, M.J.; Tafticht, T.; Doumbia, M.L.; Mutombo, N.M.-A. Dynamic Stability of Wind Power Flow and Network Frequency for a High Penetration Wind-Based Energy Storage System Using Fuzzy Logic Controller. Energies 2021, 14, 4111. [CrossRef]

68. Hoe, O.K.; Ramasamy, A.K.; Yin, L.J.; Verayiah, R.; Marsadek, M.B.; Abdillah, M. Hybrid Control of Grid-Feeding and Fuzzy Logic Fault Detection in Solving Voltage Dynamic Problem within the Malaysian Distribution Network. Energies 2021, 14, 3545. [CrossRef]

69. Napole, C.; Barambones, O.; Derbeli, M.; Cortajarena, J.A.; Calvo, I.; Alkorta, P.; Bustamante, P.F. Double Fed Induction Generator Control Design Based on a Fuzzy Logic Controller for an Oscillating Water Column System. Energies 2021, 14, 3499. [CrossRef]

70. Allani, M.Y.; Riahi, J.; Vergura, S.; Mami, A. FPGA-Based Controller for a Hybrid Grid-Connected PV/Wind/Battery Power System with AC Load. Energies 2021, 14, 2108. [CrossRef]

71. Hassan, T.-u.; Abbassi, R.; Jerbi, H.; Mehmood, K.; Tahir, M.F.; Cheema, K.M.; Elavarasan, R.M.; Ali, F.; Khan, I.A. A Novel Algorithm for MPPT of an Isolated PV System Using Push Pull Converter with Fuzzy Logic Controller. Energies 2020, 13, 4007. [CrossRef]

72. Girovský, P.; Žilková, J.; Kaňuch, J. Optimization of Vehicle Braking Distance Using a Fuzzy Controller. Energies 2020, 13, 3022. [CrossRef]

73. Hussain, S.; Ali, M.U.; Park, G.-S.; Nengroo, S.H.; Khan, M.A.; Kim, H.-J.A. Real-Time Bi-Adaptive Controller-Based Energy Management System for Battery-Supercapacitor Hybrid Electric Vehicles. Energies 2019, 12, 4662. [CrossRef]

74. Aydogmus, Z. A Real-Time Robust Fuzzy-based Level Control using Programmable Logic Controller. Elektron. Elektrotech. 2015, 21, 13-17. [CrossRef]

75. Leso, M.; Zilkova, J.; Pastor, M.; Dudrik, J. Fuzzy Logic Control of Soft-Switching DC-DC Converter. Elektron. Elektrotech. 2016, 22, 3-7. [CrossRef]

76. Huangyuan, W.; Shuanghong, W.; Keran, S.; Sun, J. Design Novel Fuzzy Logic Controller of IPMSM for Electric Vehicles. Elektron. Elektrotech. 2014, 20, 35-41. [CrossRef] 
77. Parvin, K.; Al-Shetwi, A.Q.; Hannan, M.A.; Jern, K.P. Modelling of Home Appliances Using Fuzzy Controller in Achieving Energy Consumption and Cost Reduction. Elektron. Elektrotech. 2021, 27, 15-25. [CrossRef]

78. Öztürk, N. Speed Control for DC Motor Drive based on Fuzzy and Genetic PI Controller-A Comparative Study. Elektron. Elektrotech. 2012, 123, 43-48. [CrossRef]

79. Su, I.-J.; Tsai, C.-C.; Sung, W.T. Area temperature system monitoring and computing based on adaptive fuzzy logic in wireless sensor networks. Appl. Soft Comput. 2012, 12, 1532-1541. [CrossRef]

80. Sabahi, K.; Ghaemi, S.; Pezeshki, S. Application of type-2 fuzzy logic system for load frequency control using feedback error learning approaches. Appl. Soft Comput. 2014, 21, 1-11. [CrossRef]

81. Rastelli, J.P.; Peñas, M.S. Fuzzy logic steering control of autonomous vehicles inside roundabouts. Appl. Soft Comput. 2015, 35, 662-669. [CrossRef] 